\title{
VULNERABILIDADE FÍSICA DO LITORAL SUL DE PERNAMBUCO À EROSÃO
}

\author{
Daniele Laura Bridi MALLMANN ${ }^{1} *$ \\ Tereza Cristina Medeiros de ARAÚJO ${ }^{1}$
}

\begin{abstract}
RESUMO
O presente estudo apresenta uma proposta metodológica para estimar a vulnerabilidade de segmentos costeiros à erosão através de uma abordagem semiquantitativa, bem como sua aplicação para 14 praias do litoral sul de Pernambuco. Análises como esta constituem importantes ferramentas no processo de gerenciamento costeiro, tendo em vista que possibilitam o estabelecimento de áreas prioritárias para a gestão. Assim, após pesquisa sobre os métodos existentes para esse fim, foi elaborada uma metodologia através da qual dados qualitativos e quantitativos são codificados em pesos proporcionais à sua influência sobre um Índice de Vulnerabilidade Global (IVG). Por sua vez, o IVG é calculado a partir de cinco Índices Parciais de Vulnerabilidade (IPVs), relacionados: à morfologia costeira, à presença de atributos naturais, à influência marinha, aos processos costeiros e a fatores antrópicos. Os resultados obtidos demonstram que $32,1 \%$ da linha de costa analisada pode ser classificada como de baixa vulnerabilidade no que tange aos riscos de erosão. Áreas que apresentam grau de vulnerabilidade muito alto $(21,3 \%)$ coincidem com os núcleos urbanos ou porções deles, sugerindo um controle muito mais estrutural/ antrópico do que natural/dinâmico sobre a vulnerabilidade global. Ademais, foi possível identificar quais são as variáveis de maior influência sobre a vulnerabilidade de cada praia e identificar três grupos de praias cuja natureza da vulnerabilidade se assemelha, estando relacionada: (a) à morfologia costeira e aos processos costeiros; (b) à influência antrópica e aos processos costeiros; e (c) à influência antrópica e aos atributos naturais. Conclui-se que a metodologia aqui proposta é simples e factível mesmo para áreas cujas informações são escassas, como é o caso do litoral sul de Pernambuco. Os resultados obtidos com a sua aplicação podem vir a orientar o processo de ocupação das praias localizadas na área de estudo, tendo em vista que na maior parte delas a urbanização ainda é incipiente, condição ideal para a implementação de planos de manejo preventivos.
\end{abstract}

Palavras chave: proposta metodológica; análise de vulnerabilidade; gerenciamento costeiro; praias arenosas

\section{ABSTRACT}

This study proposes a methodology to estimate the vulnerability of coastal segments to erosion through a semi-quantitative approach and its application to 14 beaches on the southern coast of Pernambuco State, Northeast Brazil. Such analyses are important tools in the process of coastal management, aimed to establish priority areas for management. After researching existing methods of coastal vulnerability assessment, a new method was prepared through which qualitative and quantitative data are encoded in weights proportional to their influence on a Coastal Vulnerability Index (CVI). In turn, the CVI is calculated from five Partial Vulnerability Indexes (PVI), related to: coastal morphology, presence of natural attributes, marine influence, coastal processes and human factors. Results show that $32.1 \%$ of the shoreline analyzed can be classified as of low vulnerability with regard to the risks of erosion. Areas which have very high degree of vulnerability $(21.3 \%)$ coincide with the urban areas or portions of them, suggesting a more structural control / anthropic than natural / dynamic on the global vulnerability. Furthermore, it was possible to identify the variables of greater influence on the vulnerability of each beach and identify three groups of beaches whose nature of vulnerability is similar, being related to: (a) the coastal morphology and coastal processes, (b) the anthropic influence and coastal processes, and (c) the anthropic influence and natural attributes. It is concluded that the methodology proposed here is simple and feasible even in areas where information is scarce, such as the southern coast of Pernambuco State. The results of its application may

Contatos: ${ }^{1}$ Laboratório de Oceanografia Geológica

Departamento de Oceanografia,

Universidade Federal de Pernambuco,

Cidade Universitária, 50740550 - Recife , PE

*E-mail: danielemallmann@gmail.com 
MALMANN, D. L.B; ARAÚJO, T. C. M. Vulnerabilidade física do litoral sul de Pernambuco à erosão

well guide the process of occupation of the beaches located in the study area, taking into consideration that in most of them the urbanization is still incipient, which is the ideal condition for the implementation of management plans for prevention.

Keywords: methodological proposal, vulnerability analysis, coastal management, sand beaches

\section{INTRODUÇÃO}

As praias representam sistemas transicionais, dinâmicos e sensíveis, em constante ajuste às flutuações dos níveis de energia locais. Sua principal função ambiental consiste na atuação como zona tampão, protegendo a costa da ação direta da energia do oceano (Hoefel, 1998).

Como ambientes dinâmicos, as praias estão sujeitas a um complexo sistema de forças e processos, dos quais são produtos (Manso et. al., 2001). A estabilidade de uma praia é a situação na qual essas forças trabalham igualando perdas e ganhos de sedimentos. Tal equilíbrio, no entanto, nem sempre é possível, tendo em vista que a idéia de que uma praia natural deve ser estável não é sustentada ao longo do tempo geológico (Bird \& Schwartz, 1985).

A erosão marinha, caracterizada pelo recuo da linha de costa em direção ao continente e decorrente do balanço sedimentar negativo, promove a perda de importantes habitats costeiros, além de grandes perdas econômicas. Cerca de $70 \%$ das praias arenosas do mundo encontram-se atualmente em processo de erosão (Bird \& Schwartz, op.cit.). Alguns fatores podem ser apontados como causadores de processos erosivos junto à linha de costa e estão relacionados principalmente: ao suprimento de sedimentos, à energia das ondas e marés, à posição relativa do nível do mar (eustasia, movimento crustal e subsidência) e às obras de engenharia costeira (Toldo Jr., 2006).

A urbanização, que se dá cada vez mais próxima à linha de costa, impede o processo natural e cíclico de retirada e reposição de sedimentos. Assim, a crescente ocupação da zona costeira, bem como a demanda acelerada pelos seus recursos, vem intensificando os efeitos da erosão nessas áreas, tornando-as mais vulneráveis ao processo erosivo (Lélis, 2003; Esteves, 2004). Neste contexto, a atribuição de graus de vulnerabilidade à erosão para diferentes segmentos tem se mostrado uma ferramenta importante para o planejamento e gerenciamento da zona costeira.

Apesar da grande aplicabilidade, pesquisas envolvendo análises de vulnerabilidade costeira ainda não estão consolidadas. O próprio conceito de vulnerabilidade, quando se fala de zonas costeiras, ainda é uma questão bastante controversa, tendo em vista a vasta gama de termos utilizados para sua definição (Dutriex et al., 2000; McCarthy et al., 2001, Boruff et al., 2005; Gouldby \& Samuels, 2005). Na presente análise, é adotada a estrutura formal da vulnerabilidade, proposta por Ionescu et al. (2005), segundo a qual o conceito de vulnerabilidade independe do domínio do conhecimento específico e do sistema de interesse, sendo apenas requerida para seu estudo a especificação de três conceitos primários: (a) a entidade da qual se deseja avaliar a vulnerabilidade; (b) o estímulo ao qual a entidade pode ser mais ou menos vulnerável; e (c) os critérios utilizados para analisar a interação entre entidade e estímulo.

No que se refere às abordagens metodológicas, tampouco existe um consenso em torno da mais adequada, uma vez que aquelas disponíveis ainda estão em fase de teste e requerem maiores debates científicos. Uma tendência verificada é a adoção de abordagens semi-quantitativas, em geral, com o uso de Índices de Vulnerabilidade Costeira (IVCs) (Azuz-Adeath, 2002; Kokot et al., 2004; Pendleton et al., 2004; Boruff et al., 2005; Diez et al., 2007). Tais análises se utilizam da codificação de variáveis qualitativas e quantitativas em pesos proporcionais à sua influência sobre o grau de vulnerabilidade de um sistema e, para a integração destes pesos, não raro, fazem uso de algoritmos como o adotado na presente análise aplicada a parte do litoral de Pernambuco (descrito na seção seguinte).

O litoral supracitado, seguindo tendência global, tem suportado um grande crescimento, constituindo a região de maior densidade demográfica do estado (Lima, 2003; Gregório, 2004). Segundo Lira (1997), em vários pontos da costa o processo erosivo já é 
percebido em intensidades que variam de moderada a severa. Suas causas locais e regionais, no entanto, permanecem desconhecidas. Em determinados trechos, tentativas de minimizar o processo de recuo da linha de costa por meio da construção de obras já se fazem necessárias (FINEP/UFPE, 2008). No litoral sul, área do presente estudo, trabalhos anteriores diagnosticaram variações da linha de costa da magnitude de dezenas de metros em diversos pontos, as quais foram atribuídas, em sua maioria, à dinâmica natural (Costa, 2002). Estudos sistemáticos, no entanto, inexistem para tal região, tendo sido feitos somente estudos pontuais (no tempo e no espaço), principalmente a partir da década de 90.

Este estudo apresenta uma análise de vulnerabilidade dos diversos segmentos costeiros do litoral sul de Pernambuco (Tamandaré, Barreiros e São José da Coroa Grande) à erosão, a fim de representar o potencial de reação da linha de costa às forçantes que atuam no sistema praial e aos efeitos do uso na região. Pretende-se, desta forma, sugerir setores prioritários para o gerenciamento costeiro na área.

\section{MATERIAL E MÉTODOS}

O litoral sul de Pernambuco abrange uma faixa de $99 \mathrm{~km}$ a partir da foz do Rio Jaboatão, até a foz do Rio Persinunga, compreendendo os municípios de Cabo de Santo Agostinho, Ipojuca, Sirinhaém, Rio Formoso, Tamandaré, Barreiros e São José da Coroa Grande (CPRH, 2003). O presente estudo contemplou os municípios de Tamandaré, Barreiros e São José da Coroa Grande (SJCG), localizados no extremo sul do estado (Fig. 1).

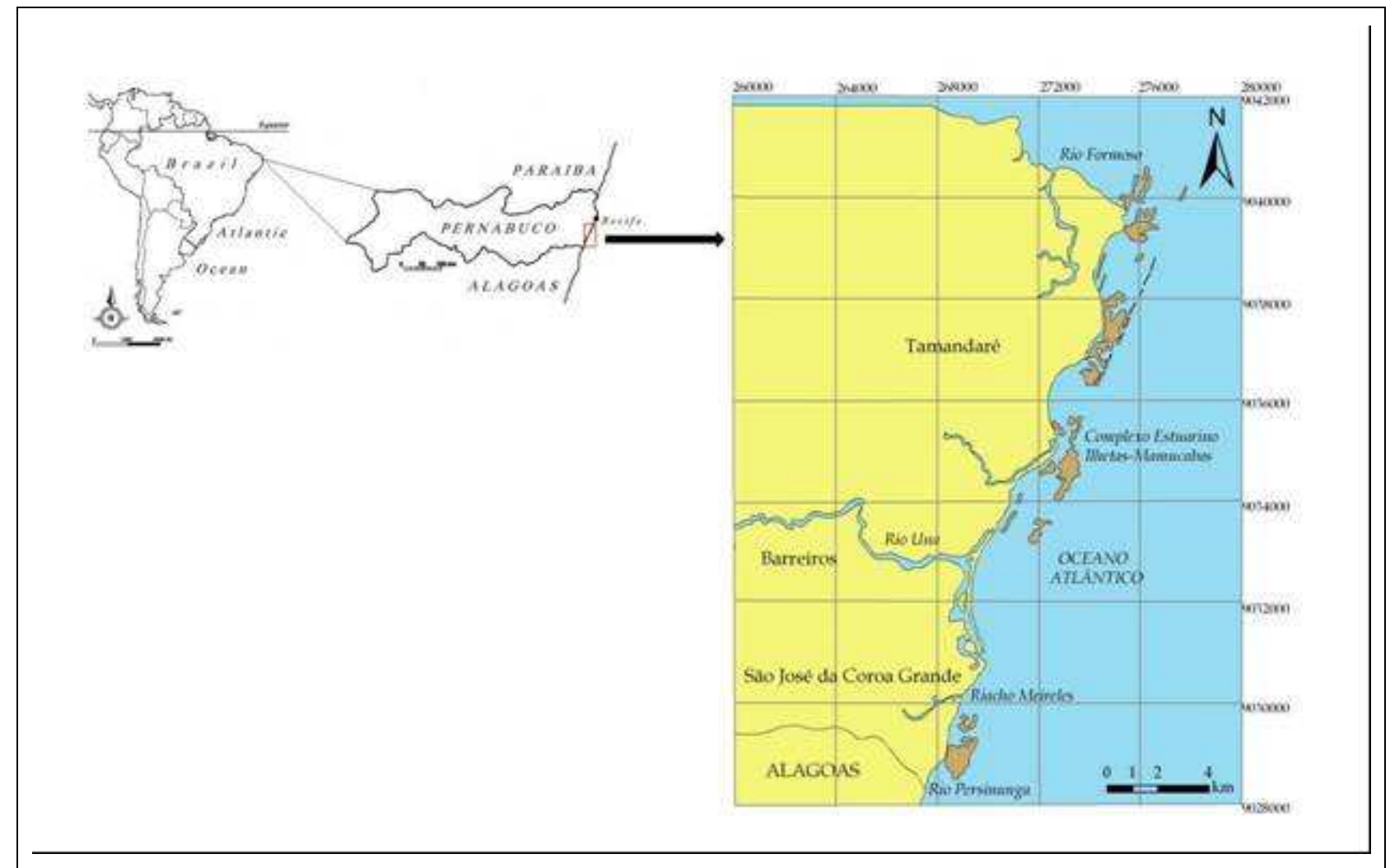

Figura 1 - Localização da área de estudo. Localização dos segmentos: (A) Carneiros; (B) Pontal de Manguinhos; (C) Campas; (D) Tamandaré - norte; (E) Tamandaré - centro; (F) Baía de Tamandaré; (G) Complexo estuarino Ilhetas-Mamucabas; (H) Mamocabinhas; (I) Porto; (J) Várzea do Una; (K) Pontal de Gravatá; (L) São José da Coroa Grande - norte; (M) São José da Coroa Grande - centro; (N) São José da Coroa Grande - sul.

Para o levantamento da linha de costa atual e a coleta de informações sobre a mesma foram feitas saídas em campo, conduzidas durante os meses de setembro de 2006, abril e setembro de 2007. A delimitação das unidades de estudo foi feita com base na homogeneidade ambiental das praias. Assim, as unidades consideradas para a coleta dos dados e para a avaliação da vulnerabilidade, sua extensão aproximada e percentual da área de estudo correspondente encontram-se na Tabela 1. 
MALMANN, D. L.B; ARAÚJO, T. C. M. Vulnerabilidade física do litoral sul de Pernambuco à erosão

Tabela 1 - Unidades consideradas para o estudo.

\begin{tabular}{|c|c|c|c|c|c|c|}
\hline Município & Segmento & & $\begin{array}{l}\text { Extensão } \\
\text { (m) }\end{array}$ & $\begin{array}{c}\% \\
\text { extensão } \\
\text { total }\end{array}$ & $\begin{array}{l}\text { Coordenadas } \\
\text { Iniciais (UTM) }\end{array}$ & $\begin{array}{l}\text { Coordenadas } \\
\text { Finais (UTM) }\end{array}$ \\
\hline Tamandaré & (A) Praia dos Carneiros & & 930 & 3,4 & $\begin{array}{c}270.772 \\
/ 9.037 .605\end{array}$ & $\begin{array}{l}271.139 / \\
9.036 .895\end{array}$ \\
\hline Tamandaré & (B) Pontal de Manguinhos & & 800 & 2,9 & $\begin{array}{l}271.139 / \\
9.036 .908\end{array}$ & $\begin{array}{l}270.814 / \\
9.036 .303\end{array}$ \\
\hline Tamandaré & (C) Praia de Campas & ) & 2.99 & 11 & $\begin{array}{l}270.814 / \\
9.036 .303\end{array}$ & $\begin{array}{l}270.311 / \\
9.033 .565\end{array}$ \\
\hline Tamandaré & (D) Tamandaré -Norte & ) & 1.43 & 5,2 & $\begin{array}{l}270.311 / \\
9.033 .565\end{array}$ & $\begin{array}{l}270.233 / \\
9.032 .212\end{array}$ \\
\hline Tamandaré & (E) Tamandaré - Centro & ) & 1.32 & 4,8 & $\begin{array}{l}270.233 / \\
9.032 .212\end{array}$ & $\begin{array}{l}269.450 / \\
9.031 .206\end{array}$ \\
\hline Tamandaré & (F) Baía de Tamandaré & ) & 3.56 & 13 & $\begin{array}{l}269.450 / \\
9.031 .206\end{array}$ & $\begin{array}{l}268.360 / \\
9.028 .359\end{array}$ \\
\hline Tamandaré & $\begin{array}{l}\text { (G) Complexo Estuarino } \\
\text { Ilhetas-Mamucabas }\end{array}$ & & 600 & 2,2 & $\begin{array}{l}268.385 / \\
9.028 .296\end{array}$ & $\begin{array}{l}268.364 / \\
9.027 .761\end{array}$ \\
\hline Barreiros & $\begin{array}{l}\text { (H) Praia de } \\
\text { Mamocabinhas }\end{array}$ & ) & 2.77 & 10,1 & $\begin{array}{l}268.364 / \\
9.027 .761\end{array}$ & $\begin{array}{l}266.779 / \\
9.025 .848\end{array}$ \\
\hline Barreiros & (I) Praia do Porto & ) & 1.19 & 4,4 & $\begin{array}{l}266.773 / \\
9.025 .847\end{array}$ & $\begin{array}{l}266.166 / \\
9.024 .822\end{array}$ \\
\hline $\begin{array}{l}\text { São José da } \\
\text { Coroa Grande }\end{array}$ & (J) Várzea do Una & ) & 4.74 & 17,4 & $\begin{array}{l}266.183 / \\
9.024 .684\end{array}$ & $\begin{array}{l}265.540 / \\
9.020 .304\end{array}$ \\
\hline $\begin{array}{l}\text { São José da } \\
\text { Coroa Grande }\end{array}$ & (K) Pontal do Gravatá & ) & 2.48 & 9,1 & $\begin{array}{l}265.454 / \\
9.020 .018\end{array}$ & $\begin{array}{l}264.911 / \\
9.018 .000\end{array}$ \\
\hline $\begin{array}{l}\text { São José da } \\
\text { Coroa Grande }\end{array}$ & $\begin{array}{l}\text { (L) São José da Coroa } \\
\text { Grande - Norte }\end{array}$ & ) & 1.01 & 3,7 & $\begin{array}{l}264.864 / \\
9.017 .939\end{array}$ & $\begin{array}{l}264.374 / \\
9.017 .073\end{array}$ \\
\hline $\begin{array}{l}\text { São José da } \\
\text { Coroa Grande }\end{array}$ & $\begin{array}{l}\text { (M) São José da Coroa } \\
\text { Grande - Centro }\end{array}$ & ) & 2.54 & 9.3 & $\begin{array}{l}264.374 / \\
9.017 .073\end{array}$ & $\begin{array}{l}263.436 / \\
9.014 .912\end{array}$ \\
\hline \multirow[t]{2}{*}{$\begin{array}{l}\text { São José da } \\
\text { Coroa Grande }\end{array}$} & $\begin{array}{l}\text { (N) São José da Coroa } \\
\text { Grande - Sul }\end{array}$ & & 940 & 3.4 & $\begin{array}{l}263.436 / \\
9.014 .912\end{array}$ & $\begin{array}{l}263.227 / \\
9.014 .020\end{array}$ \\
\hline & TOTAL & & 27.300 & 100 & - & - \\
\hline
\end{tabular}

Para cada segmento foi preenchida uma planilha com os dados ambientais da praia e tomadas fotografias. Em todo o percurso foi realizado um perfil longitudinal da linha de costa, por meio da marcação de waypoints com GPS (Global Positioning System) de mão modelo Garmin 48, cujo erro máximo é estimado em $10 \mathrm{~m}$. O indicador utilizado foi a marca da maré mais alta (High water line - $H W L$ ), representada pelo avanço da última maré alta e identificada pela linha de umidade que separa a praia seca da praia úmida.

Fotografias aéreas verticais impressas, datadas de 1961 e tomadas durante levantamento conduzido pela Seção de Aerofotogrametria da Diretoria de Hidrografia e Navegação (DHN), foram obtidas junto ao Departamento de Oceanografia. As mesmas foram convertidas para o formato digital e a partir de então, foi confeccionado um mosaico de forma controlada, unindo pontos comuns de diferentes fotografias com percentual de sobreposição. Para fins de registro, foi tomado como base cartográfica o mapeamento planialtimétrico do Ministério do Interior (1974) na escala 1:25.000, o qual adota o Sistema de Referência Geodésico Córrego Alegre. 
Com o uso de um Sistema de Informações Geográficas (SIG), os dados referentes à posição multitemporal da linha de costa foram organizados, e o deslocamento foi estimado por meio da criação de transectos perpendiculares à linha de costa-base (assumida a mais antiga como tal), com espaçamento de 50 metros entre cada um deles. O método utilizado para o cálculo das taxas anuais de deslocamento de linha de costa é conhecido como "ponto final", o qual consiste em medir a distância entre as posições da linha de costa em duas épocas distintas e dividir o resultado (em metros) pelo intervalo de tempo existente entre elas (em anos) (CERC, 1986; DOUGLAS et al., 1998; Farias, 2008).

A compilação de dados secundários, assim como a sistematização dos dados coletados em campo, foi essencial para que a escolha das variáveis envolvidas estivesse de acordo com as informações disponíveis. Ademais, tal escolha foi orientada por estudos préexistentes referentes ao tema (Dal Cin \& Simeoni, 1994; Esteves \& Finkl, 1998; Thieler \& Hammar-Klose, 1999; Souza \& Suguio, 2003). Desta forma, foram eleitas 21 variáveis agrupadas em 5 categorias, utilizadas para o cálculo dos índices parciais de vulnerabilidade (IPVs). Todas elas se encontram resumidas a seguir (Tab. 2), com seus intervalos e pesos correspondentes.

Tabela 2 - Variáveis utilizadas para o cálculo dos índices de vulnerabilidade e seus pesos correspondentes.

\begin{tabular}{|c|c|c|c|}
\hline Descritores & & Pesos & \\
\hline Condições Morfológicas & 1 & 2 & 3 \\
\hline Tipo de orla & Abrigada & Semi-abrigada & Exposta \\
\hline Largura da pós-praia & Ampla (>70m) & Média (30-70m) & Estreita $(<30 \mathrm{~m})$ \\
\hline Inclinação da pós-praia & Íngreme $\left(>30^{\circ}\right)$ & Moderada $\left(5-30^{\circ}\right)$ & Suave $\left(<5^{\circ}\right)$ \\
\hline Diâmetro médio do grão* & $\begin{array}{l}\text { Areia grossa }(0,5- \\
1 \mathrm{~mm})\end{array}$ & $\begin{array}{c}\text { Areia média }(0,25- \\
0,5 \mathrm{~mm})\end{array}$ & $\begin{array}{l}\text { Areia Fina }(0,125- \\
\quad 0,25 \mathrm{~mm})\end{array}$ \\
\hline Atributos Naturais & 1 & 2 & 3 \\
\hline Recifes paralelos à costa & Presente & - & Ausente \\
\hline Manguezal & Presente & - & Ausente \\
\hline Distância de foz de rio & Distante & $\begin{array}{c}\text { Moderada } \\
\text { (adjacências) }\end{array}$ & Próximo (segmento) \\
\hline Dunas ou cordões arenosos & Presente & - & Ausente \\
\hline Afloramento rochoso & Ausente & - & Presente \\
\hline Influência Marinha & 1 & 2 & 3 \\
\hline Variação de maré & Micro $(<2 \mathrm{~m})$ & Meso $(2-4 m)$ & Macro $(>4 m)$ \\
\hline Tipo de arrebentação & Deslizante & - & Mergulhante \\
\hline Largura da zona de surfe & Ampla & Média & Estreita \\
\hline Praia recreativa na maré alta & Sim & - & Não \\
\hline Altura significativa de onda* & $<0,5 \mathrm{~m}$ & $0,5-1 \mathrm{~m}$ & $>1 \mathrm{~m}$ \\
\hline Processos Costeiros & 1 & 2 & 3 \\
\hline Indicadores de erosão & Ausente & - & Presente \\
\hline Indicadores de acumulação & Presente & - & Ausente \\
\hline
\end{tabular}


MALMANN, D. L.B; ARAÚJO, T. C. M. Vulnerabilidade física do litoral sul de Pernambuco à erosão

Taxa anual de deslocamento de linha de costa **
$>0,5 \mathrm{~m}$.ano-1 de $-0,5$ a $0,5 \mathrm{~m}$. ano- 1

$>-0,5 \mathrm{~m}$. ano-1

\begin{tabular}{|c|c|c|c|}
\hline Influência Antrópica & 1 & 2 & 3 \\
\hline Urbanização do beach front & Baixa $(<30 \%)$ & Moderada (30-70\%) & Alta $(>70 \%)$ \\
\hline Tipo de construções & Casas & - & Prédios \\
\hline $\begin{array}{l}\text { Local onde a primeira faixa de construções } \\
\text { está assentada }\end{array}$ & $\begin{array}{l}\text { Atrás da pós- } \\
\text { praia }\end{array}$ & Pós-praia & Praia \\
\hline Estrutura de proteção costeira & Ausente & - & Presente \\
\hline Taxa de crescimento demográfico* & $<10 \%$. ano-1 & 10 a $20 \%$. ano-1 & $>20 \%$.ano-1 \\
\hline
\end{tabular}

* Dados obtidos ou calculados a partir de informações pré-existentes

** Dados obtidos a partir de fotografias aéreas e caminhamentos com GPS (intervalo de 1961-2006)

Demais dados: obtidos por medições e observações em campo

Com o propósito de integrar as variáveis, foi escolhida uma abordagem semiquantitativa, na qual todos os atributos, qualitativos ou quantitativos, foram codificados em pesos (1, 2 e 3 ) de acordo com seu grau de influência sobre a vulnerabilidade da costa à erosão. Todos os dados referentes a cada segmento foram organizados em planilhas eletrônicas. Os índices parciais de vulnerabilidade foram calculados separadamente, com base em Thieler e Hammar-Klose (1999), usando algoritmo que consiste na raiz quadrada do produto das variáveis codificadas dividido pelo número de variáveis (Eq. I).

(Equação I)

$$
I P V=\sqrt{\frac{\left(v_{1} * v_{2} * v_{3} * \ldots v_{n}\right)}{n}}
$$

Onde: $v=$ variável e $n=$ número de variáveis.

Os IPVs foram integrados no índice global de vulnerabilidade (IGV) a partir do seu somatório (Eq. II).

$$
\text { (Equação II) } \quad I G V=\sum I P V s
$$

A fim de expressar a vulnerabilidade em percentual, os valores finais do IGV foram divididos por um denominador comum, representado pelo somatório dos valores máximos possíveis de cada IPV.

Os valores calculados resultaram em números adimensionais, de forma tal que se fez necessário um tratamento estatístico para sua interpretação. Assim, para estabelecer os intervalos entre as diferentes categorias de vulnerabilidade, foram desenvolvidas rotinas em código Fortran com o uso de software específico a fim de considerar todas as combinações possíveis entre as variáveis da checklist. A partir do resultado desta análise combinatória foram calculados os quartis e estabelecida sua relação com o nível de vulnerabilidade para cada um dos índices parciais, os quais ficaram assim definidos (Tab. 3):

Tabela 3 - Relação entre os intervalos dos valores e os graus de vulnerabilidade.

\begin{tabular}{ll}
\multicolumn{1}{c}{ Intervalo } & \multicolumn{1}{c}{ Grau de vulnerabilidade } \\
\hline [Valor mínimo - Primeiro quartil (25\%)] & Baixo \\
]Primeiro quartil - Segundo quartil (50\%)] & Moderado \\
]Segundo quartil - Terceiro quartil (75\%)] & Alto \\
]Terceiro quartil - Valor máximo] & Muito alto
\end{tabular}

Para analisar a semelhança entre a natureza da vulnerabilidade dos segmentos, os índices parciais foram organizados numa matriz e submetidos a uma análise de similaridade do tipo Bray-Curtis. 


\section{RESULTADOS}

\section{Índices Parciais de Vulnerabilidade (IPVs)}

\section{Índice Parcial de Vulnerabilidade Associado à Morfologia Costeira (IPVMC)}

Em percentual de linha de costa, a maior parte da extensão percorrida foi classificada como orla exposta ( $55 \%$, correspondentes às praias de Campas, Baía de Tamandaré, Porto, Várzea do Una e Pontal do Gravatá). Embora algumas delas se tratem de baías, apresentam concavidade pouco pronunciada e incidência direta de ondas, contribuindo para o aumento do IPVMC, o qual é função, ainda, da largura e inclinação da pós-praia e do diâmetro médio do grão.

Aproximadamente $96,6 \%$ da extensão foram classificados, em função da morfologia, como apresentando um grau de vulnerabilidade muito alto. Os restantes 3,4\% correspondem à Praia dos Carneiros, a única abrigada entre as estudadas. A heterogeneidade da área quanto à morfologia costeira pode ser observada na Figura 2.

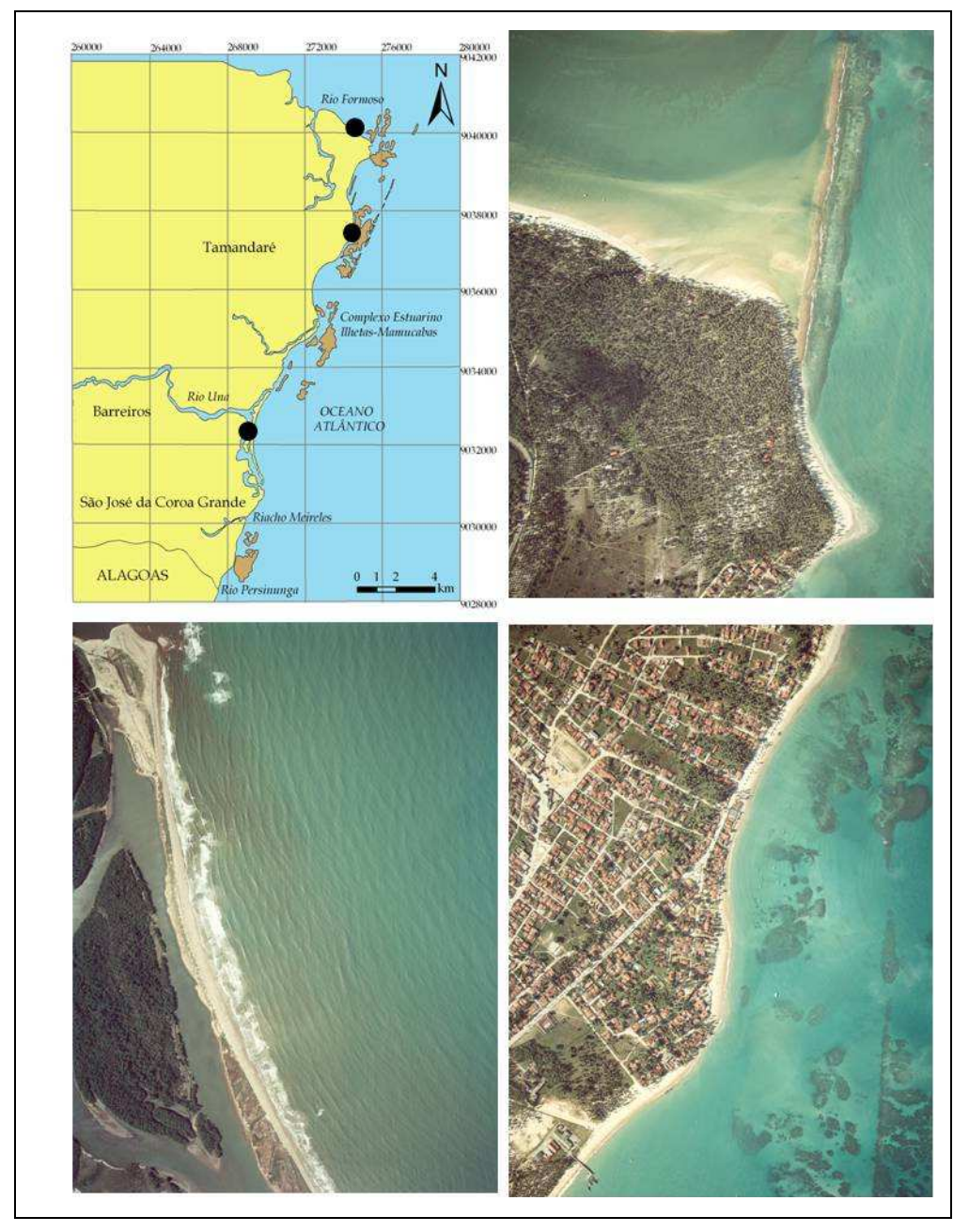

Figura 2 - Heterogeneidade da área em relação à morfologia (sentido horário): localização das fotografias (de norte para sul); Praia dos Carneiros - orla abrigada; Tamandaré (centro) - orla semi-abrigada; praia da Várzea do Una - orla exposta (fotografias aéreas datadas do ano de 2002 e cedidas pelo Ministério do Planejamento, Orçamento e Gestão).

\section{(IPVAN)}

Índice Parcial de Vulnerabilidade Associado à Presença de Atributos Naturais

O IPVAN, calculado com base na presença/ ausência de recifes, manguezais, dunas, desembocaduras de rios e afloramentos rochosos, apresentou valores entre 1,34 (Praia dos Carneiros, Tamandaré - norte e centro, complexo estuarino Ilhetas-Mamucabas, Pontal do Gravatá e São José da Coroa Grande - sul) e 3,29 (Praias de Mamocabinhas e Porto). Desta 
MALMANN, D. L.B; ARAÚJO, T. C. M. Vulnerabilidade física do litoral sul de Pernambuco à erosão

forma, quanto à presença de atributos naturais que atuam intensificando ou amenizando a vulnerabilidade da linha de costa à erosão, a área de estudo foi classificada nas categorias moderada $(28,2 \%)$, alta $(29 \%)$ e muito alta $(42,8 \%)$ (Figs. 3 e 4$)$.

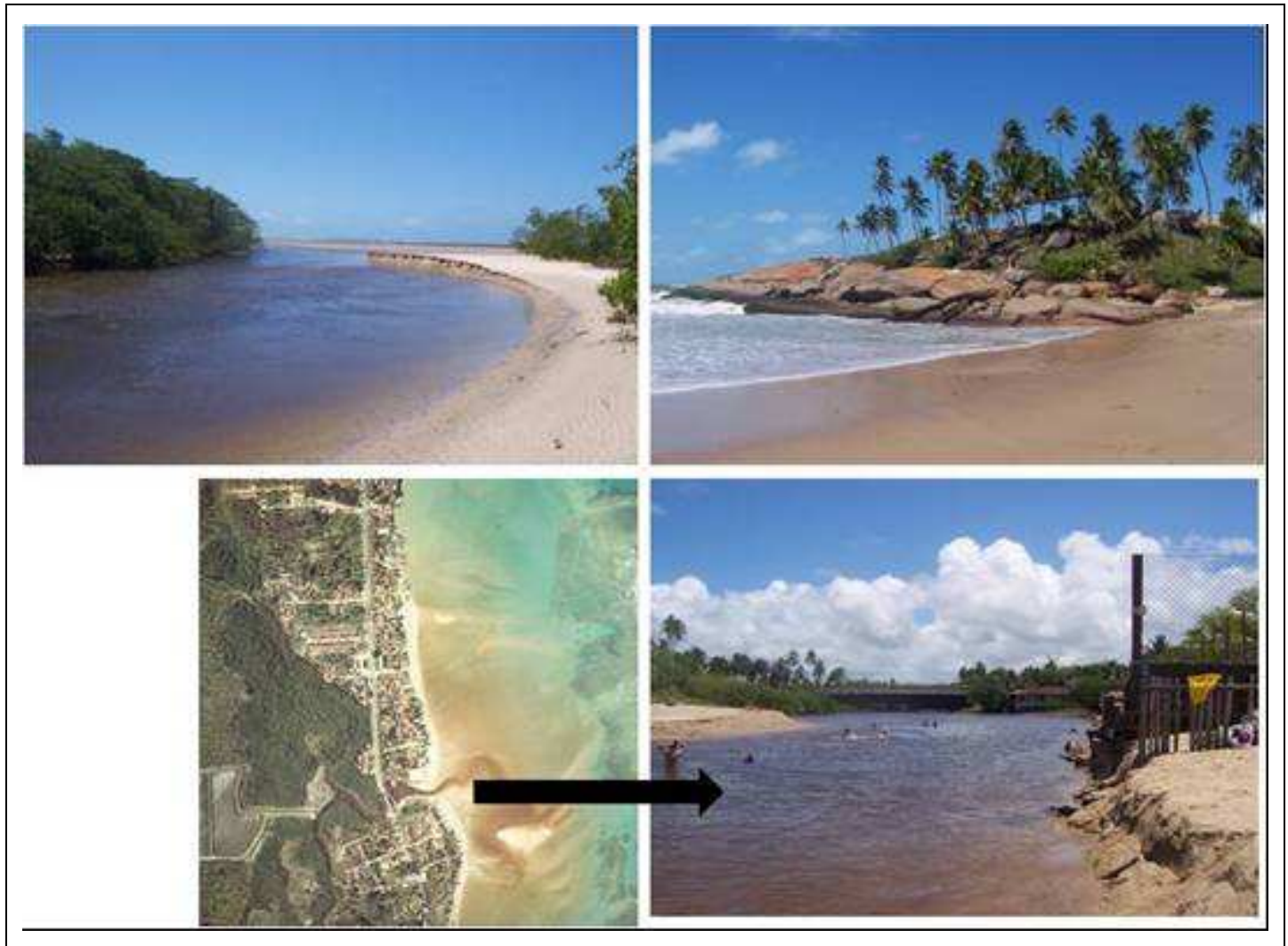

Figura 3 - Presença de fatores que aumentam o IPVAN (sentido horário): desembocadura no complexo estuarino Ilhetas-Mamucabas; afloramento rochoso entre a Várzea do Una e a Praia do Porto; foz do rio Persinunga (sul de São José da Coroa Grande fotografia aérea cedida pelo Ministério do Planejamento, Orçamento e União). 


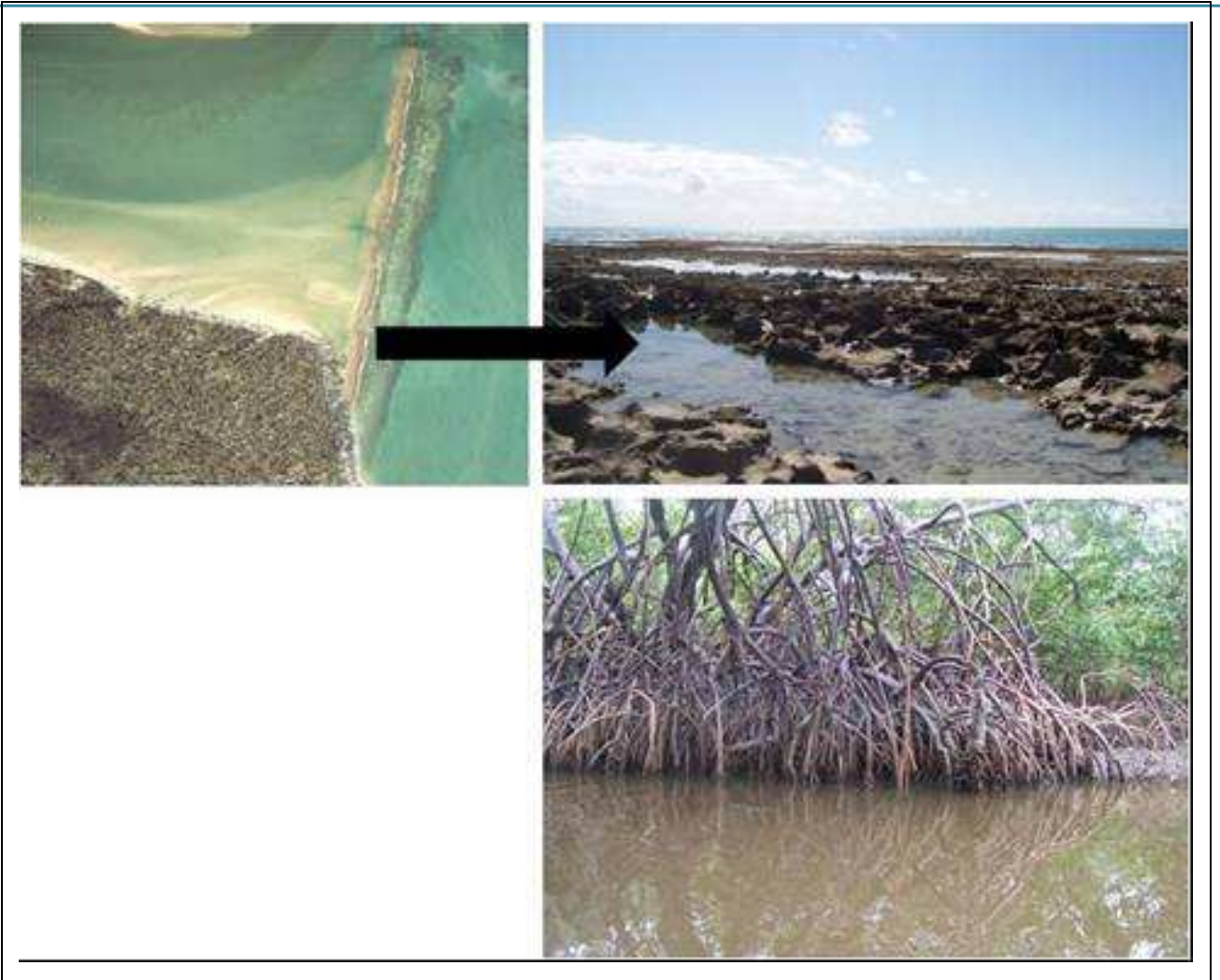

Figura 4 - Presença de fatores que reduzem o IPVAN (sentido horário): recife protegendo a costa junto à Praia dos Carneiros (fotografia aérea cedida pelo Ministério do Planejamento, Orçamento e União); manguezal na Várzea do Una.

\section{Índice Parcial de Vulnerabilidade Associado à Influência Marinha (IPVIM)}

Em função da presença de linhas de beachrocks paralelas à linha de costa, a maior parte das praias apresenta arrebentação do tipo deslizante, na qual boa parte da energia das ondas é dissipada antes de chegar à face praial. Tal característica contribui para a redução do IPVIM. Os segmentos extensos, de concavidade leve e com características de orla exposta apresentaram maior influência marinha e se limitam à Baía de Tamandaré e à Várzea do Una. Valores mínimos e máximos deste índice parcial foram calculados para a praia central de Tamandaré $(0,89)$ e Baía de Tamandaré $(3,79)$, respectivamente.

Em relação à influência marinha, $34,1 \%$ da costa foram classificados como moderadamente vulnerável. Nas classes baixa, alta e muito alta vulnerabilidade foram enquadrados, respectivamente, $8,2 \% ; 27,3 \%$ e $30,4 \%$ da extensão. A diversidade das praias estudadas quanto à influência marinha é mostrada a seguir (Figs. 5 e 6).

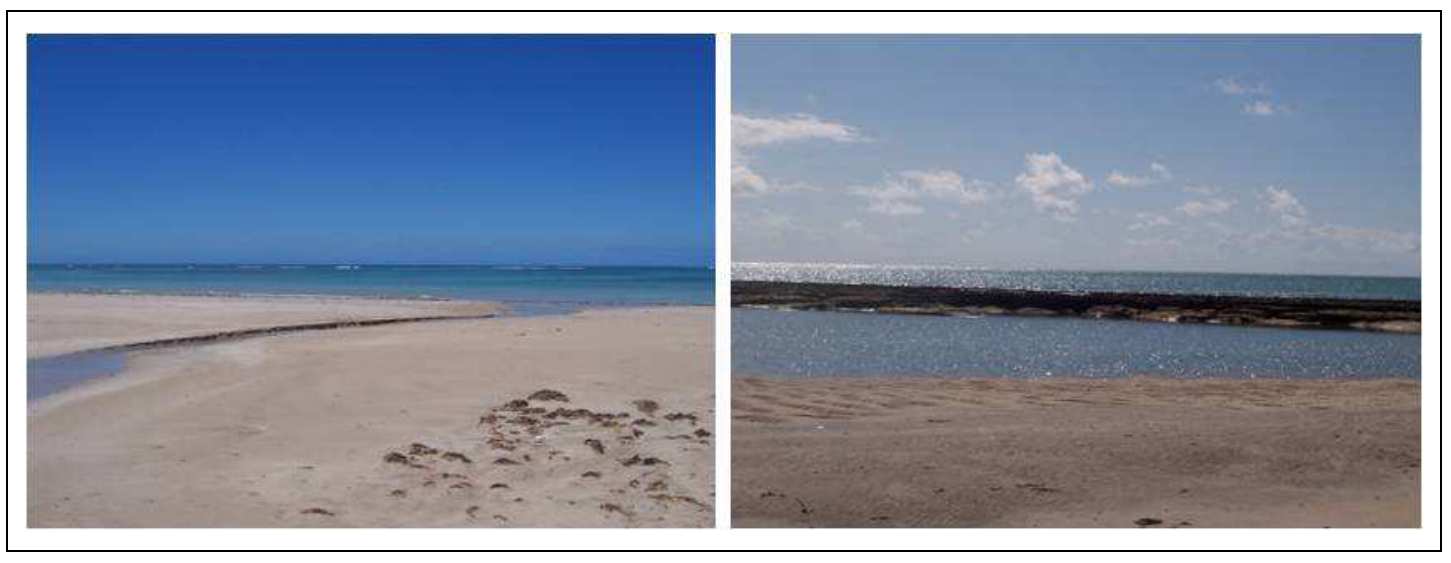


MALMANN, D. L.B; ARAÚJO, T. C. M. Vulnerabilidade física do litoral sul de Pernambuco à erosão

Figura 5 - Praias de baixo IPVIM: praia de Tamandaré - centro, segmento que apresentou menor IPVIM (esquerda); Praia dos Carneiros, área protegida da incidência direta das ondas pela presença de beachrocks (direita).

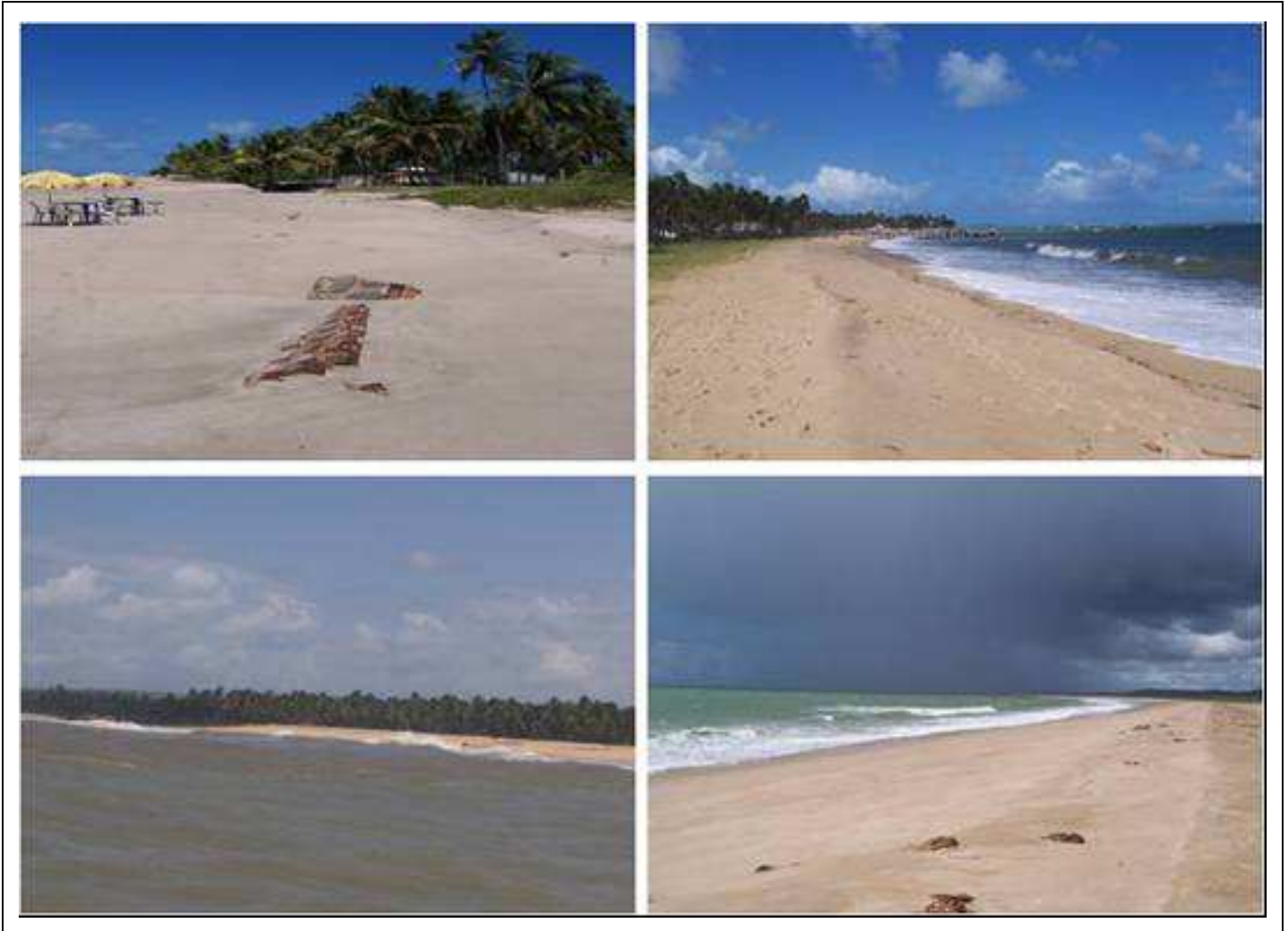

Figura 6 - Praias de elevado IPVIM (sentido horário): marca da maré alta mostrando a inexistência de praia recreativa durante tal estágio (Tamandaré - norte); Baia de Tamandaré, área com IPVIM máximo, arrebentação do tipo mergulhante e estreita zona de surf (vista para norte); praia da Várzea do Una (vista para sul) e a mesma praia vista do mar, mostrando intensa incidência de ondas responsável pelo alto IPVIM do local.

\section{Índice Parcial de Vulnerabilidade Associado aos Processos Costeiros (IPVPC)}

O IPVPC incorpora em si uma das mais importantes variáveis quando se fala de erosão costeira: a taxa de deslocamento de linha de costa (DLC). Sob a ótica desta taxa, os segmentos Pontal de Manguinhos e Várzea do Una apresentaram as maiores taxas negativa e positiva, respectivamente: $-1,85 \mathrm{~m} / \mathrm{ano}$ e $+1,97 \mathrm{~m} / \mathrm{ano}$. O deslocamento da linha de costa ao longo da área de estudo pode ser visualizado a seguir (Fig. 7). 


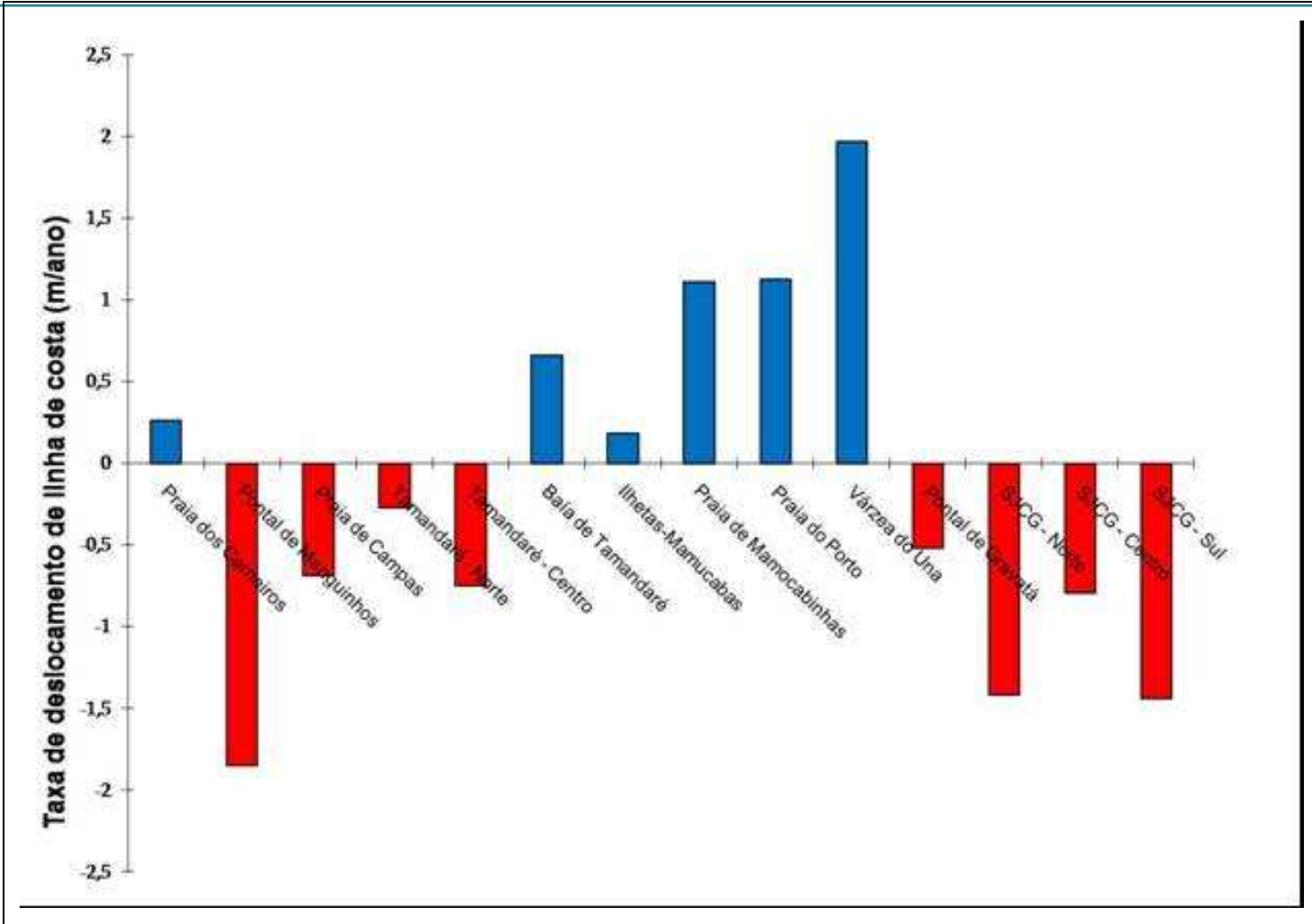

Figura 7 - Taxa média anual de deslocamento de linha de costa calculada para cada segmento.

Os valores calculados para este índice ficaram entre 1 (mínimo, para os segmentos Várzea do Una e Baía de Tamandaré) e 3 (máximo, para as praias de Campas, Tamandaré - centro, SJCG - norte, centro e sul e os Pontais de Manguinhos e Gravatá). Aproximadamente $46,4 \%$ da extensão foram classificados, quanto a este índice, como apresentando um grau de vulnerabilidade muito alto. Nas categorias de vulnerabilidade alta, moderada e baixa foram enquadrados, respectivamente, $14,5 \% ; 8,6 \%$ e $30,4 \%$ da linha de costa.

\section{Índice Parcial de Vulnerabilidade Associado à Influência Antrópica (IPVIA)}

Este índice é função de variáveis relacionadas ao uso e ocupação da praia, tais como: percentual de urbanização do beachfront, tipo de construções, local onde a primeira faixa de construções está assentada e existência de obras de contenção da erosão. Ademais, é considerada a taxa anual de crescimento demográfico, a qual apresenta o inconveniente de não refletir as informações da faixa litorânea somente, tendo em vista que os levantamentos são feitos por município, mas que foi mantida devido à inexistência de dados específicos para a orla. Os valores calculados estão compreendidos entre 0,45 (Várzea do Una) e 3,29 (Tamandaré - Norte e Centro e SJCG - Centro). Visto que se trata de uma área relativamente preservada, a maior extensão da linha de costa analisada $(73,5 \%)$ apresentou vulnerabilidade baixa, em relação a este IPV. Nas categorias alta e muito alta foram classificados, respectivamente, $7,1 \%$ e $19,4 \%$ da linha de costa.

Altos IPVIAs foram calculados para cinco segmentos da costa estudada e estão associados aos dois núcleos urbanos que se encontram desenvolvidos junto à linha de costa (Tamandaré e São José da Coroa Grande) bem como às suas adjacências. Nestes trechos, os efeitos da erosão já estão sendo sentidos e tentativas de minimizar o problema já podem ser observadas (Fig. 8). 
MALMANN, D. L.B; ARAÚJO, T. C. M. Vulnerabilidade física do litoral sul de Pernambuco à erosão

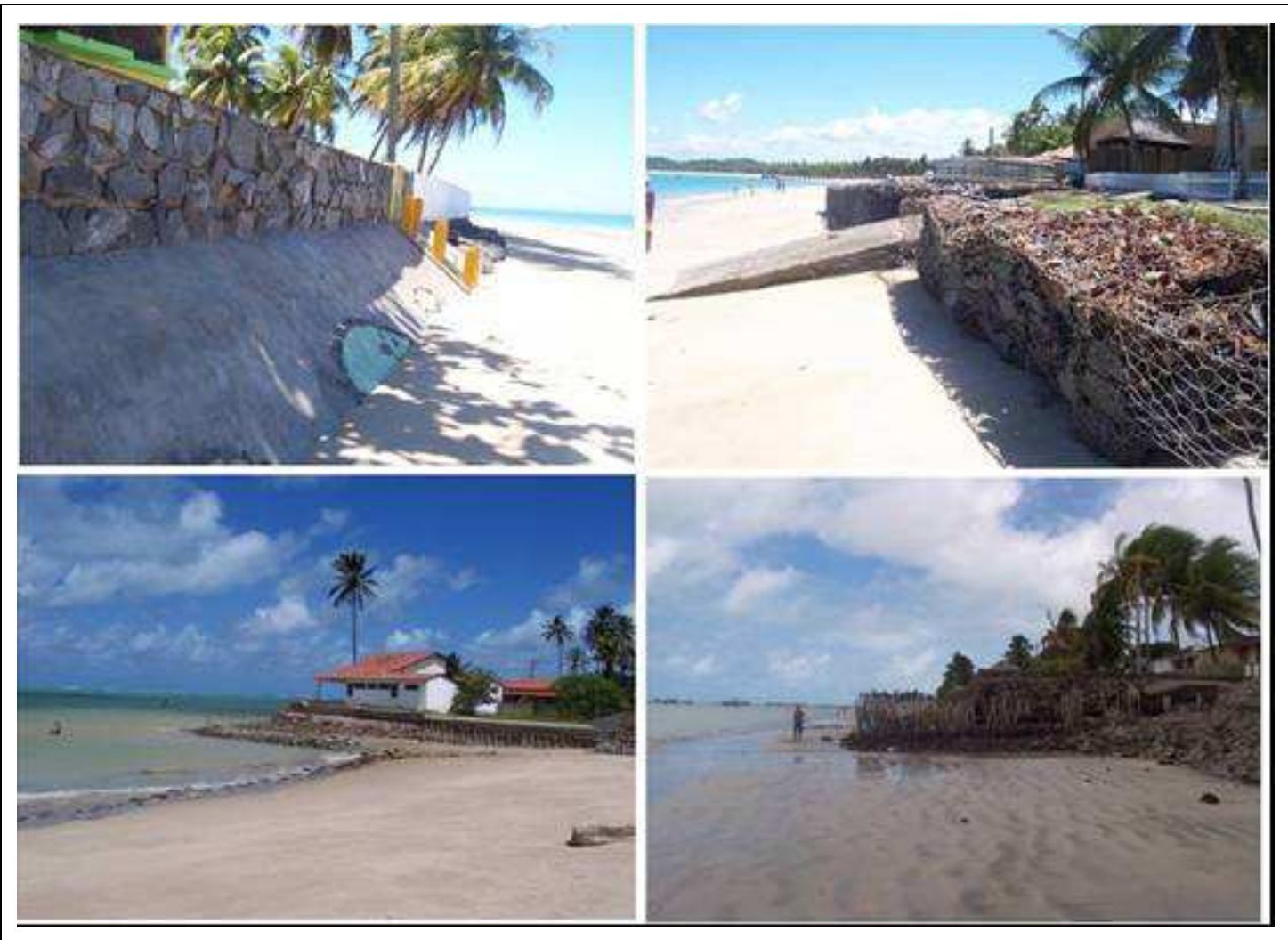

Figura 8 - Praias com elevado IPVIA (sentido horário): obras de contenção da erosão (muros e gabiões) na região central de Tamandaré; edificações avançando o estirâncio, e enrocamentos, ambos localizados na porção norte de São José da Coroa Grande.

A variabilidade da área quanto à ocupação da orla pode ser facilmente observada (Fig. 9) e reflete, em parte, a densidade demográfica dos municípios, cujos valores aproximados para Tamandaré, Barreiros e São José da Coroa Grande correspondem a 95, 180 e 248 $\mathrm{hab} / \mathrm{km}^{2}$, respectivamente.

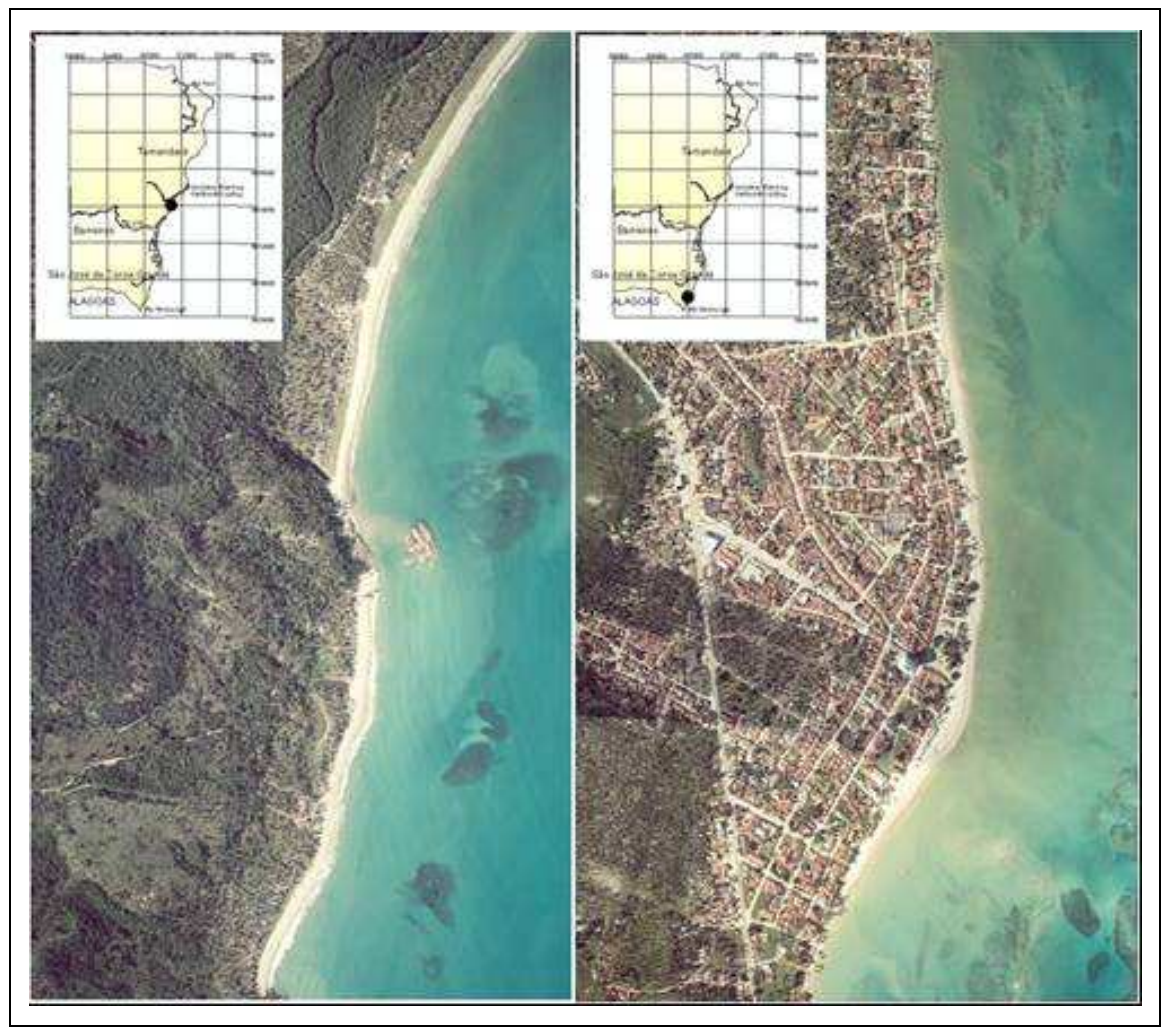


Figura 9 - Praias do Porto e Mamocabinhas (parte), área de ocupação rarefeita (esquerda); malha urbana de São José da Coroa Grande, área de maior adensamento populacional da área de estudo (direita) (Fotografias aéreas cedidas pelo Ministério do Planejamento, Orçamento e Gestão).

\section{Índice Global de Vulnerabilidade (IGV)}

\section{Estabelecimento de áreas prioritárias para o Gerenciamento Costeiro}

A integração dos cinco índices parciais de vulnerabilidade pelo seu somatório resultou no IGV. Pelo somatório dos IPVs máximos possíveis obtidos pela análise combinatória, chegou-se a um denominador comum para os IGVs, o qual possibilitou que a vulnerabilidade global fosse expressa em percentual (Tab. 4). Os limites que nortearam a classificação deste percentual em categorias de vulnerabilidade são apresentados na tabela seguinte (Tab. 5).

Tabela 4 - Vulnerabilidade parcial e global (expressa em percentual) para cada segmento.

\begin{tabular}{cccccccc}
\hline Segmento & IPVMC & IPVAN & IPVIM & IPVPC & IPVIA & IGV & \% Vulnerabilidade \\
\hline Praia dos Carneiros & 2,12 & 1,34 & 1,10 & 1,41 & 0,63 & 6,60 & $\mathbf{2 5 , 4 4}$ \\
Pontal de Manguinhos & 3,00 & 1,90 & 1,55 & 3,00 & 0,63 & 10,08 & $\mathbf{3 8 , 8 6}$ \\
Praia de Campas & 3,67 & 2,32 & 1,55 & 3,00 & 0,89 & 11,43 & $\mathbf{4 4 , 0 6}$ \\
Tamandaré - Norte & 3,00 & 1,34 & 1,55 & 1,41 & 3,29 & 10,59 & $\mathbf{4 0 , 8 2}$ \\
Tamandaré - Centro & 3,00 & 1,34 & 0,89 & 3,00 & 3,29 & 11,52 & $\mathbf{4 4 , 4 1}$ \\
Baía de Tamandaré & 3,00 & 1,90 & 3,79 & 1,00 & 0,63 & 10,32 & $\mathbf{3 9 , 7 8}$ \\
Ilhetas-Mamucabas & 2,45 & 1,34 & 1,55 & 2,45 & 0,63 & 8,42 & $\mathbf{3 2 , 4 6}$ \\
Praia de Mamocabinhas & 2,45 & 3,29 & 2,19 & 1,73 & 0,63 & 10,29 & $\mathbf{3 9 , 6 7}$ \\
Praia do Porto & 3,00 & 3,29 & 2,19 & 1,73 & 0,63 & 10,84 & $\mathbf{4 1 , 7 9}$ \\
Várzea do Una & 3,00 & 2,32 & 3,29 & 1,00 & 0,45 & 10,06 & $\mathbf{3 8 , 7 8}$ \\
Pontal de Gravatá & 3,00 & 1,34 & 1,55 & 3,00 & 0,63 & 9,52 & $\mathbf{3 6 , 7 0}$ \\
SJCG - Norte & 3,00 & 1,90 & 1,55 & 3,00 & 2,19 & 11,64 & $\mathbf{4 4 , 8 7}$ \\
SJCG - Centro & 3,67 & 1,90 & 2,19 & 3,00 & 3,29 & 14,05 & $\mathbf{5 4 , 1 6}$ \\
SJCG - Sul & 3,00 & 1,34 & 2,19 & 3,00 & 2,19 & 11,72 & $\mathbf{4 5 , 1 8}$ \\
\hline
\end{tabular}

Tabela 5 - Valores usados para classificar os IGVs em graus de vulnerabilidade.

\begin{tabular}{llll}
\hline Quartil & Valor & Percentual & Grau de Vulnerabilidade \\
\hline Primeiro & 10,07 & 38,80 & Baixo \\
Segundo & 10,46 & 40,30 & Moderado \\
Terceiro & 11,50 & 44,32 & Alto \\
Máximo & 15,05 & 54,16 & Muito Alto \\
\hline
\end{tabular}

Aproximadamente $32,1 \%$ da linha de costa estudada puderam ser enquadrados na categoria "baixa vulnerabilidade". Nas categorias moderada, alta e muito alta foram classificados 26,1\%; 20,5\% e 21,3\%, respectivamente (Fig. 10). A espacialização dos resultados pode ser visualizada na Figura 11. 
MALMANN, D. L.B; ARAÚJO, T. C. M. Vulnerabilidade física do litoral sul de Pernambuco à erosão

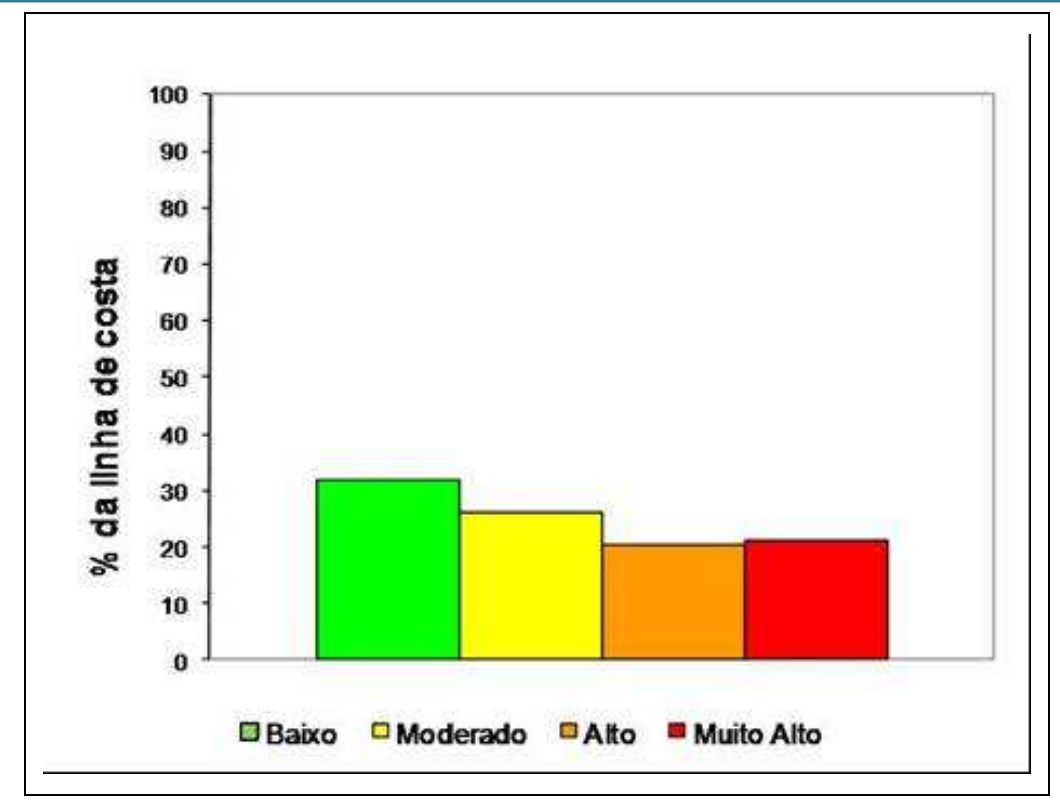

Figura 10 - Percentual da linha de costa enquadrada em cada categoria de vulnerabilidade. 


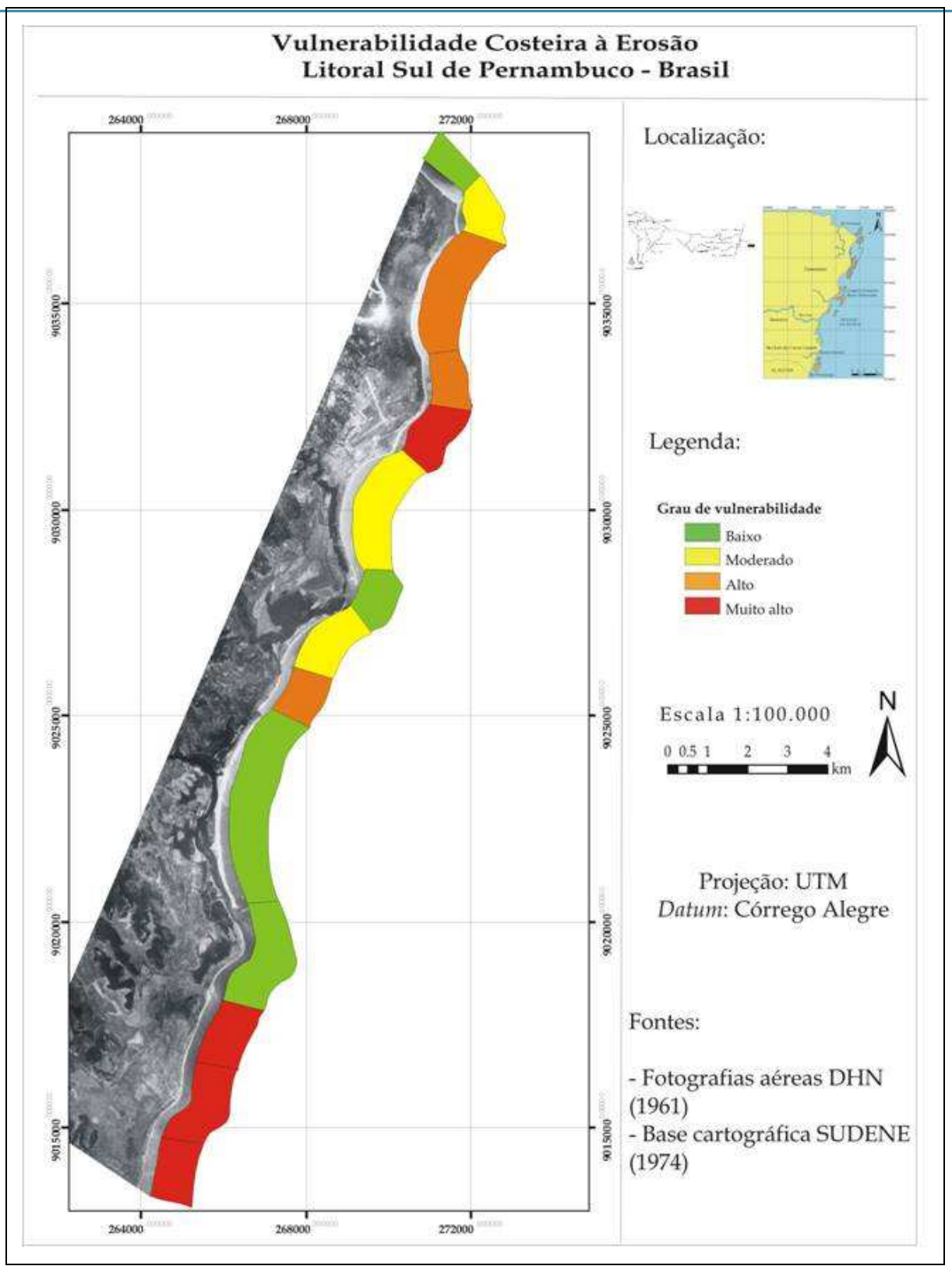

Figura 11 - Grau de vulnerabilidade global atribuído a cada segmento estudado.

\section{Natureza da vulnerabilidade}

Quanto à natureza da vulnerabilidade, a análise de similaridade resultou em 3 grupos distintos (corte a 90\%), conforme mostra o dendrograma (Fig.12). Os grupos são a seguir descritos: 
MALMANN, D. L.B; ARAÚJO, T. C. M. Vulnerabilidade física do litoral sul de Pernambuco à erosão

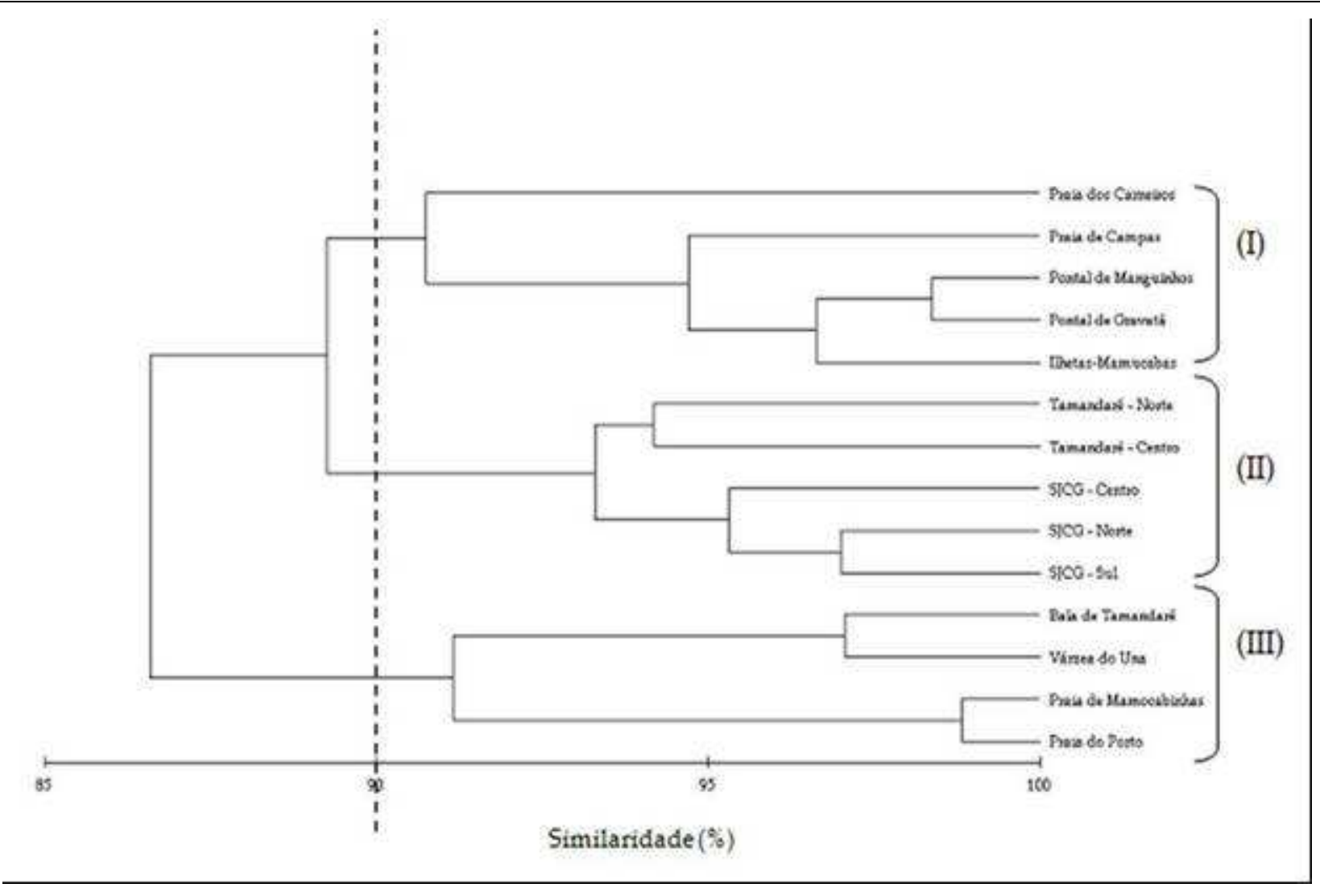

Figura 12 - Dendrograma agrupando as praias cuja natureza da vulnerabilidade se assemelha.

(I) Praia dos Carneiros, Pontal de Manguinhos, Praia de Campas, complexo estuarino Ilhetas-Mamucabas e Pontal do Gravatá

Praias que apresentam os mais baixos valores relacionados às influências antrópica e marinha. Trata-se de áreas pouco ou nada urbanizadas (à exceção de Campas), nas quais as variáveis de maior peso na determinação da vulnerabilidade são aquelas associadas à morfologia da costa e/ou aos processos costeiros (Fig. 13). 


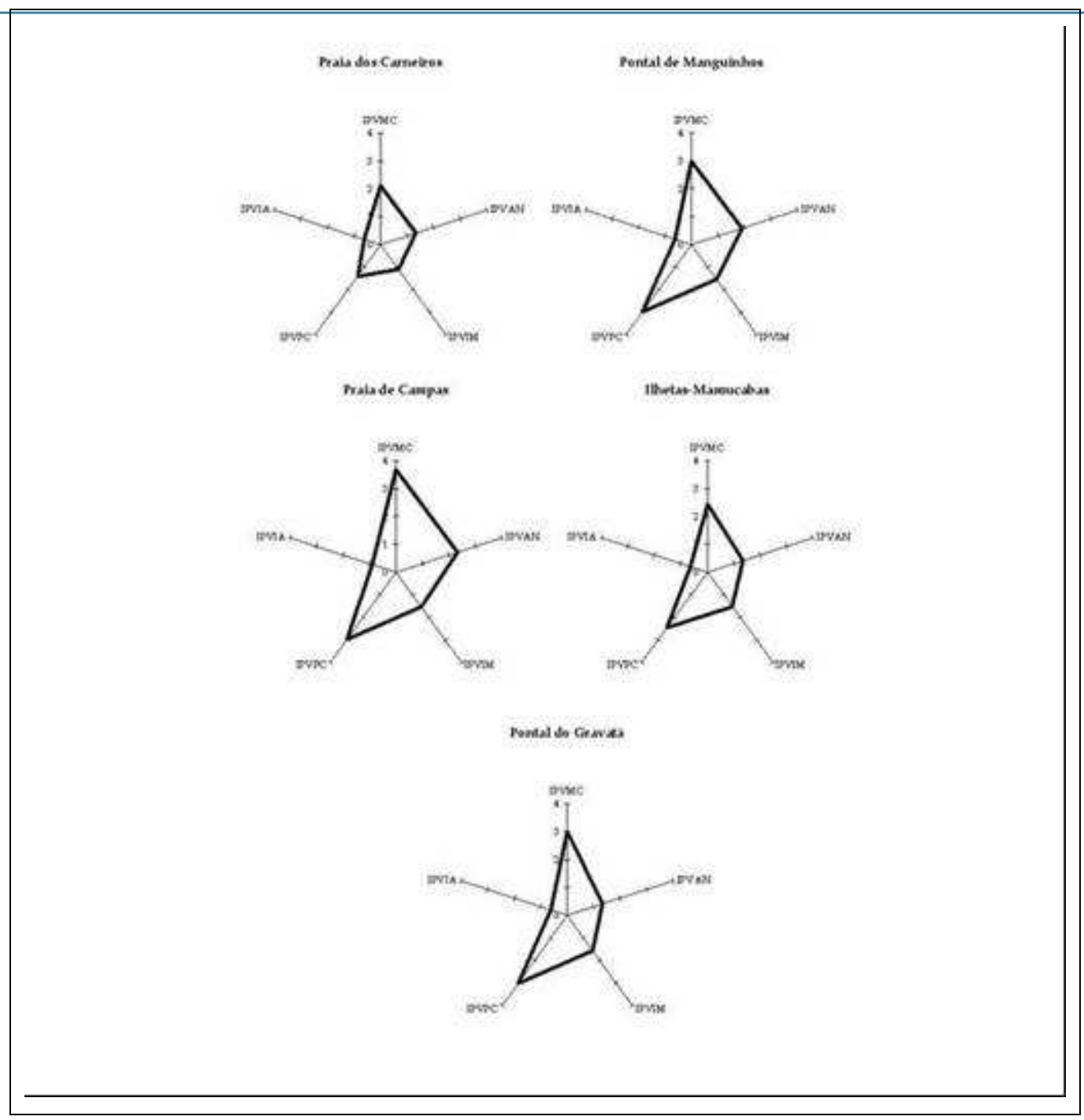

Figura 13 - Diagramas radiais mostrando a influência de cada um dos IPVs na vulnerabilidade global de cada praia classificada no grupo I.

(II) Tamandaré - norte e centro e São José da Coroa Grande - norte, centro e sul

Praias que apresentam os mais altos valores de IPVIA. Trata-se de trechos onde 0 desenvolvimento urbano se fez muito próximo da linha de costa e, em determinados casos, ocupa setores do sistema praial (pós-praia ou estirâncio).

Outro índice determinante da vulnerabilidade nessas áreas é o IPVPC, o qual se mostra elevado para quase todos os segmentos, exceto para Tamandaré - Norte, o único do grupo II que apresentou alta vulnerabilidade global. Todos os demais foram classificados como apresentando grau de vulnerabilidade muito alto (Fig. 14).

Nesses locais, é comum a presença de obras de contenção da erosão, tais como muros, enrocamentos e gabiões. Todos os segmentos aqui enquadrados se encontram em processo de erosão na escala de tempo da presente análise. As taxas de erosão, embora não sejam das mais elevadas, já promovem transtornos aos moradores e preocupam as autoridades. 
MALMANN, D. L.B; ARAÚJO, T. C. M. Vulnerabilidade física do litoral sul de Pernambuco à erosão

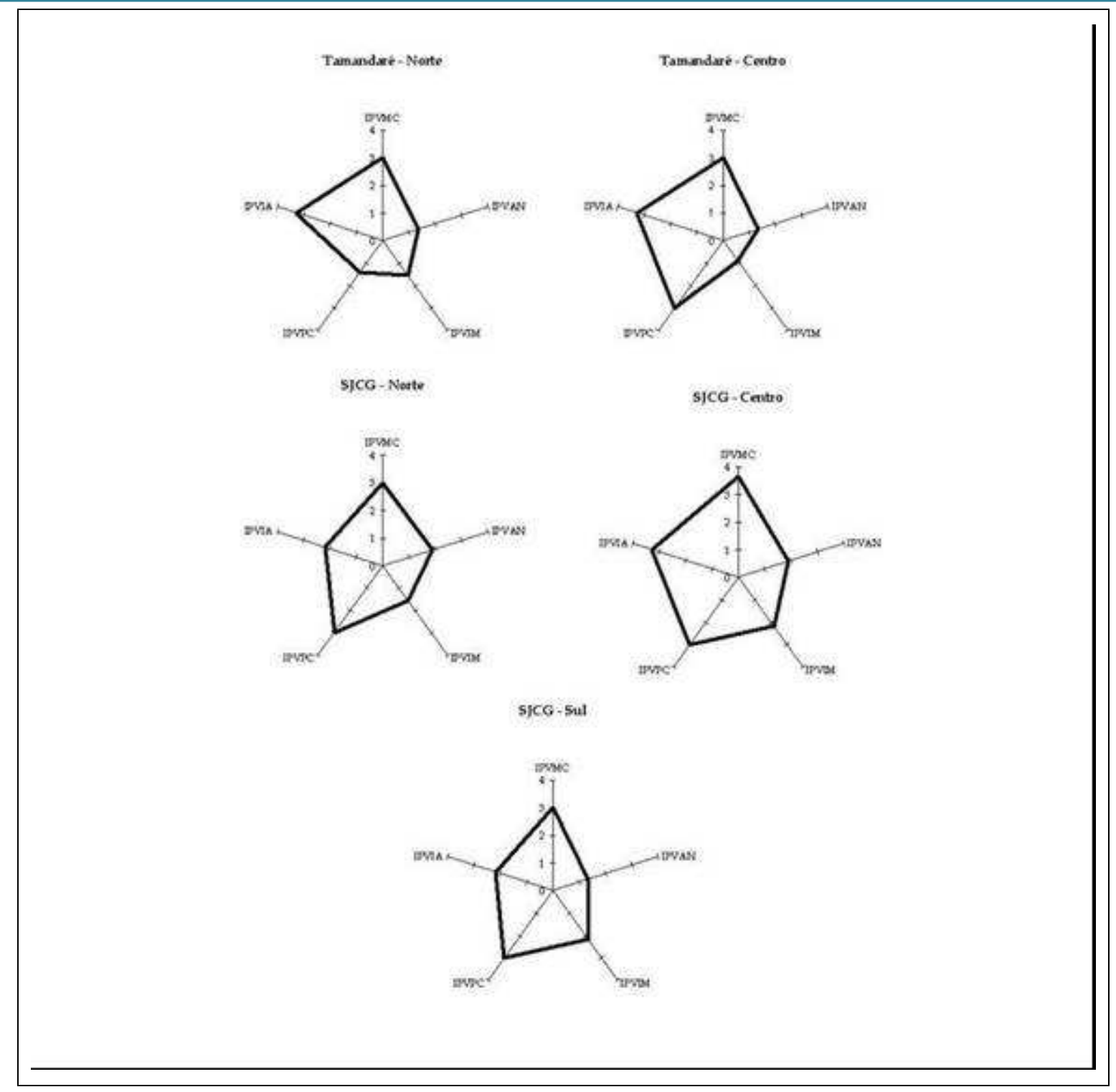

Figura 14 - Diagramas radiais mostrando a influência de cada um dos IPVs na vulnerabilidade global de cada praia classificada no grupo II.

(III) Baía de Tamandaré, Praia de Mamocabinhas, Praia do Porto e Várzea do Una

Segmentos pouco urbanizados nos quais as variáveis que mais contribuem para o IGV estão associadas à influência marinha e/ou aos atributos naturais. Segundo a análise de deslocamento de linha de costa, estes trechos têm apresentado comportamento progradante nos últimos 45 anos, motivo pelo qual, além do baixo IPVIA, apresentam ainda baixo IPVPC (Fig. 15). 


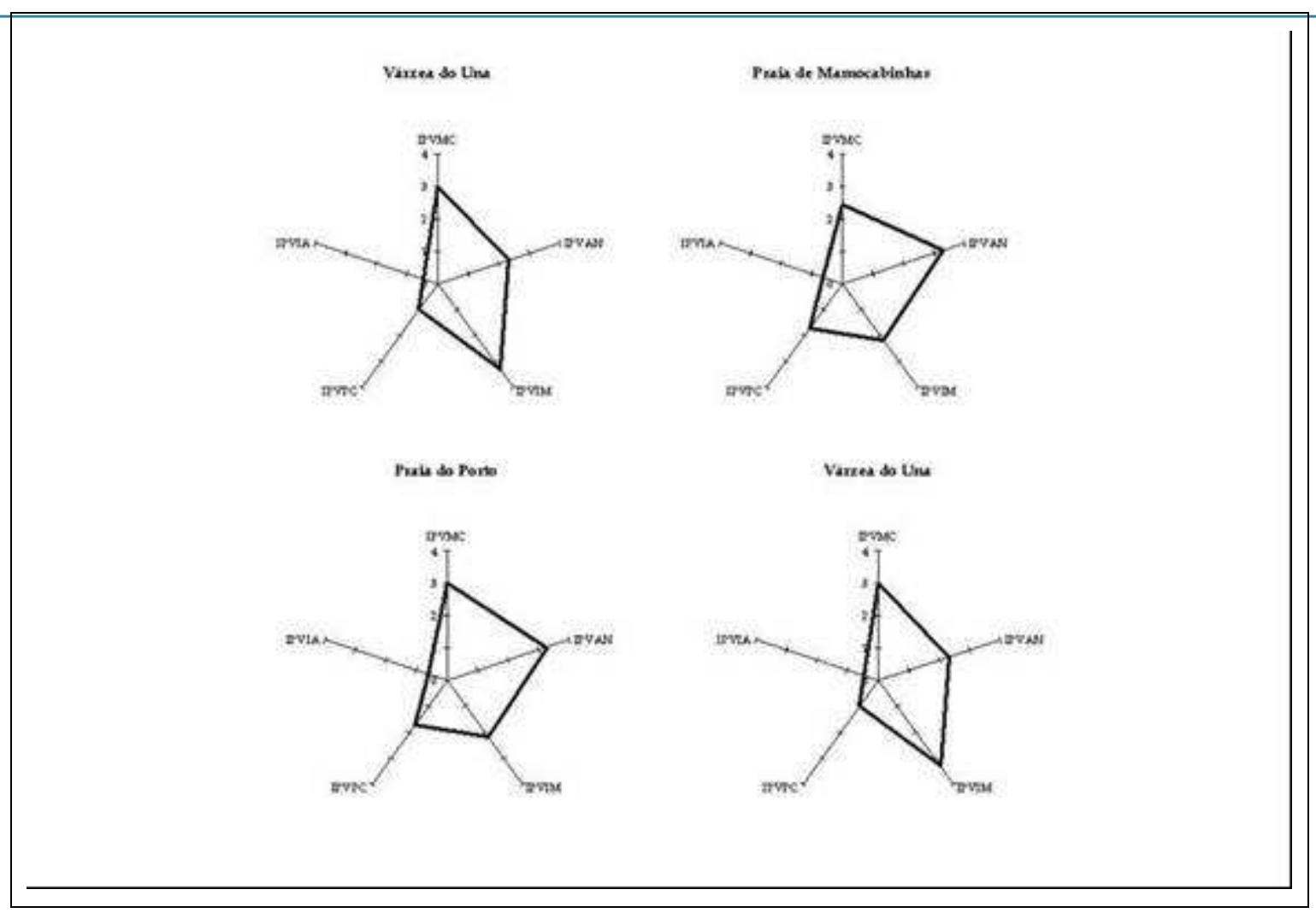

Figura 15 - Diagramas radiais mostrando a influência de cada um dos IPVs na vulnerabilidade global de cada praia classificada no grupo III.

Com base na análise das especificidades de cada unidade, podem-se priorizar áreas mais críticas, levando em consideração os fatores de maior importância na composição da vulnerabilidade global. Assim, o tipo de intervenção pode ser orientado pela origem desta vulnerabilidade: se morfológica, natural, marinha, morfodinâmica ou antrópica.

\section{DISCUSSÃo}

A espacialização dos resultados permitiu destacar a concentração dos segmentos de vulnerabilidade muito alta no extremo sul da área de estudo, junto ao núcleo urbano de São José da Coroa Grande (aproximadamente $77,3 \%$ do total da categoria). Para os demais segmentos analisados, embora ainda não haja ocupação tão densa, o desenvolvimento de complexo turísticos e empreendimentos associados podem vir a alterar as características relacionadas à ocupação e, conseqüentemente, os seus IPVIAs. Esta colocação aponta para a necessidade de novas aplicações da metodologia para a costa estudada, dada sua natureza dinâmica, especialmente diante da observação de CPRH (2003), a seguir transcrita:

"a urbanização da orla litorânea sul teve início na década de setenta com a implantação de loteamentos de veraneio cuja ocupação se deu a partir da década de oitenta e ocorre em ritmo acelerado, envolvendo aterro de mangue, maceiós e gamboas, destruição de dunas e privatização de trechos da praia através de muros, rampas e outras construções que impedem o acesso público a essas áreas. Atualmente, a ocupação da orla marítima prossegue em ritmo acentuado, com o surgimento de novos loteamentos e a implantação de infra-estrutura e equipamentos de apoio ao turismo - rodovias asfaltadas, hotéis, resorts, marinas - além de condomínios fechados."

Outra informação interessante é a coincidência entre as desembocaduras dos rios mais expressivos da região e as áreas de baixa vulnerabilidade (Rio Formoso - Praia dos Carneiros; Rios Ilhetas e Mamucabas - Ilhetas e Mamucabas; Rio Una - Várzea do Una e Pontal do Gravatá). Tal constatação sugere que estes rios podem estar atuando na região mais como fontes de contribuição no suprimento sedimentar do que como agentes erosivos, corroborando o anteriormente dito por Camargo (2005). 
Ao longo do litoral estudado, o único indicador de acreção observado foi a berma recém-vegetada, presente somente nos segmentos da Várzea do Una e Tamandaré - Norte (pequena parte). Já os indicadores de erosão incluíram coqueiros caídos, raízes expostas, mangues caídos, afloramento de lençol freático e de turfa e foram observados em praticamente todos os segmentos, inclusive em partes daqueles que se encontram em progradação. Somente em dois segmentos, Praia dos Carneiros e Baía de Tamandaré, não foram observados tais indicadores.

No que tange ao posicionamento multitemporal do da linha de costa, algumas constatações podem ser feitas de maneira qualitativa, com base na análise da sobreposição das duas linhas de costa:

- $\quad$ Segmentos em erosão, à exceção dos pontais de Manguinhos e Gravatá, coincidem com áreas de maior urbanização, sugerindo uma predominância do controle estrutural/antrópico sobre o controle dinâmico/natural no que se refere à evolução da linha de costa de médio termo nessas áreas;

- Segmentos em progradação são representados pelas praias de maior concavidade (Baía de Tamandaré, Praia de Mamocabinhas e Várzea do Una), à exceção da Praia de Campas, em sua maior porção classificada como erosiva;

- $\quad$ Segmentos de intensa dinâmica, com deslocamentos tanto perpendiculares à linha de costa (em ambos os sentidos, positivo e negativo), quanto paralelos (como pode ser visto no limite Pernambuco-Alagoas, onde a foz do Rio Persinunga parece ter migrado para sul da sua posição em 1961), são comuns junto às desembocaduras de rios, onde os controles envolvidos são muito mais dinâmicos do que estruturais. Tal comportamento é comum em tais áreas, onde, de acordo com Dean (1993), mudanças da ordem de dezenas de metros por ano são freqüentes.

No que se refere à abordagem metodológica, de acordo com Boruff et al. (2005), a inclusão de fatores relacionados tanto à exposição física quanto à ocupação humana faz com que uma análise deste gênero reflita com maior acerácia a vulnerabilidade de um local aos riscos de erosão. Isto se tornou claro no presente estudo quando foram comparadas as influências de cada índice parcial sobre a vulnerabilidade, bem como a variação espacial desta influência.

A possibilidade de destacar a variabilidade regional da vulnerabilidade, bem como a variabilidade entre seus determinantes é fundamental na orientação de políticas e iniciativas de mitigação para cada local. O estabelecimento de segmentos costeiros prioritários em planos de manejo, possível a partir de estudos como o aqui apresentado, configura tal metodologia como uma ferramenta de suporte à gestão costeira bastante interessante.

Cabe ressaltar que as variáveis incluídas no estudo, embora pareçam muitas, são apenas parte daquelas que atuam amplificando ou atenuando a vulnerabilidade da costa. Esta simplificação, no entanto, é inerente ao processo de abstração do mundo real que se faz necessário quando se representa ou modela um ambiente ou fenômeno.

Outra consideração se refere à dimensão "tempo". Embora alguns elementos temporais tenham sido incorporados à metodologia (taxas anuais de crescimento demográfico e de deslocamento da linha de costa, ambas calculadas para o período entre 1961 e 2006), é importante que se tenha em mente que o IGV se limita a um mero indicador estático das condições durante um período analisado. A maior parte dos IPVs apresenta natureza dinâmica, de forma tal, que as alterações naturais e o desenvolvimento do local, além das ações de contenção do processo erosivo podem alterar os IPVs e, em decorrência, o IGV.

\section{CONCLUSÃO}

A vulnerabilidade da linha de costa estudada foi avaliada com uma metodologia semiquantitativa relativamente simples e factível, mesmo para áreas onde informações são 
escassas, como é o caso do litoral sul de Pernambuco. Sua aplicação foi possível graças à construção de um banco de dados a partir de informações levantadas em campo, em bibliografias e geradas a partir do uso de um Sistema de Informações Geográficas.

O litoral sul de Pernambuco apresenta segmentos com características distintas no que diz respeito ao grau e aos fatores determinantes da vulnerabilidade. Cerca de $32,1 \%$ da linha de costa analisada apresenta um baixo grau de vulnerabilidade à erosão, enquanto $21,3 \%$ apresentam vulnerabilidade muito alta. A localização das áreas menos vulneráveis sugere uma relação entre estas e as desembocaduras dos rios mais expressivos da região, os quais podem estar agindo mais como fontes de contribuição sedimentar do que como agentes erosivos. Por sua vez, a localização das áreas mais vulneráveis ressalta a importância dos fatores relacionados à influência antrópica na vulnerabilidade global: mais de $3 / 4$ dos $21,3 \%$ classificados nesta categoria se concentram no extremo sul da área, junto à malha urbana de São José da Coroa Grande e, o complemento, corresponde ao centro de Tamandaré. Nas categorias intermediárias de vulnerabilidade - moderada e alta foram enquadrados, respectivamente, $26,1 \%$ e $20,6 \%$ da linha de costa.

Foi possível atribuir diferentes graus de vulnerabilidade para as praias estudadas, bem como identificar os conjuntos de fatores que mais contribuem para esta vulnerabilidade em cada uma delas. O uso de IPVs agregou informação ao IGV, de tal forma, que sua análise individual permitiu a observação de especificidades mesmo entre praias com graus de vulnerabilidade muito próximos. Assim, foram identificados três grupos de praias/ segmentos cuja natureza da vulnerabilidade se assemelha, estando relacionada: (a) à morfologia costeira e aos processos costeiros; (b) à influência antrópica e aos processos costeiros; e (c) à influência antrópica e aos atributos naturais.

Por fim, cabe observar que a metodologia aqui proposta e aplicada representa uma primeira tentativa no sentido de realizar análises de vulnerabilidade mais robustas para o litoral em questão. A evolução das variáveis semi-quantitativas para quantitativas, assim como a introdução de novas variáveis e a ponderação dos pesos para as variáveis de acordo com a sua importância através de análises estatísticas, tornariam a metodologia mais fiel à realidade ambiental das praias estudadas, além de menos sensível às pequenas variações de cada parâmetro. O cumprimento de tal sugestão, no entanto, é até o momento limitado pela escassez de dados referentes à área.

\section{REFERÊNCIAS}

AZUZ-ADEATH, I. Gross approximation on the erosive vulnerability along the Mexican Coast. Littoral, the changing coast, Porto, p. 445-451, 2002.

BIRD, E. C. F.; SCHWARTZ, M. C. The world's coastline. New York: Van Nostrand einhold, 1985. $1071 \mathrm{p}$.

BORUFF, B. J; EMRICH, C.; CUTTER, S. L. Erosion hazard vulnerability of US Coastal Counties. Journal of Coastal Research, West Palm Beach, Florida, v. 21, n. 5, p. 932-42, 2005.

CAMARGO, J. M. R. Mapeamento sonográfico da plataforma continental adjacente ao município de Tamandaré, Pernambuco, Brasil. Recife, 2005. Dissertação de mestrado, Universidade Federal de Pernambuco. 65 p.

CERC - Coastal Engineering Research Center. Measuring Shoreline Change. New York: U.S. Army. Coastal Engineering Technical Note, II-86, 7p., 1986.

COSTA, J. A. Sedimentologia, hidrodinâmica e vulnerabilidade das praias no trecho entre a foz do Rio Mamucaba (Tamandaré - PE) e a foz do Rio Persinunga (São José da Coroa Grande - PE). Recife, 2002. Dissertação de mestrado, Universidade Federal de Pernambuco. $79 \mathrm{p}$.

CPRH - AGÊNCIA ESTADUAL DE MEIO AMBIENTE E RECURSOS HÍDRICOS. Diagnóstico Sócio-ambiental do Litoral Sul de Pernambuco. Recife, 2003. 87 p.

Disponível em: <http://www.cprh.pe.gov.br/frme-index-secao.asp?idsecao=294 > Acesso em: 02 mai. 2006. 
MALMANN, D. L.B; ARAÚJO, T. C. M. Vulnerabilidade física do litoral sul de Pernambuco à erosão

DAL CIN, R.; SIMEONI, U. A model for determining the classification, vulnerability and risk in the southern coastal zone of the Marche (Italy). Journal of Coastal Research, Fort Lauderdale, Florida, v. 10, n. 1, p. 18-29, 1994.

DIEZ, P. G.; PERILLO, G. M. E.; PICCOLO, M. C. Vulnerability to sea-level rise on the coast of the Buenos Aires Province. Journal of Coastal Research, West Palm Beach, Florida, v. 23, n. 1, p. 119-126, 2007.

DOUGLAS, B. C.; CROWELL, M.; LEATHERMAN, S. P. Considerations for shoreline position prediction. Journal of Coastal Research, Royal Palm Beach, Flórida, v. 14, n. 3, p. 10251033, 1998.

DUTRIEUX, E.; CANOVAS, S.; DENIS, J.; HÉNOCQUE, Y.; QUOD, J. P. \& BIGOT, L. Guidelines for vulnerability mapping of coastal zones in the Indian Ocean. UNESCO/IOC, Paris, 2000. n. 38, 41 p.

ESTEVES, L. S.; FINKL, C. W. The problem of Critically Eroded Areas (CEA): an evaluation of Florida beaches. Journal of Coastal Research, Royal Palm Beach, Florida, SI 26, p. 11$18,1998$.

ESTEVES, L. S. Variabilidade espaço-temporal dos deslocamentos da linha de costa no Rio Grande do Sul. Porto Alegre, 2004. Tese de doutorado, Universidade Federal do Rio Grande do Sul. 139 p.

FARIAS, E. G. G. Aplicação de técnicas de geoprocessamento para a análise da evolução da linha de costa em ambientes litorâneos do estado do Ceará. Fortaleza, 2008. Dissertação de mestrado, Universidade Federal do Ceará. 109 p.

FINEP/UFPE. Monitoramento Ambiental Integrado - MAI-PE. Recife, 2008. Relatório Técnico Preliminar - Vols. 1 e 2. Financiadora de Estudos e Projetos - FINEP, Recife, 383 pp.

GOULDBY, B.; SAMUELS, P. Language of risk - Project definitions. FLOODsite Project Report T32-04-01, EU GOCE-CT. European Comission. 2005

GREGÓRIO, M. D. N. Sedimentologia e morfologia das praias do Pina e da Boa Viagem, Recife (PE) - Brasil. Recife, 2004. Dissertação de mestrado, Universidade Federal de Pernambuco. 92 p.

HOEFEL, F. G. Morfodinâmica de praias arenosas oceânicas, uma revisão bibliográfica. Itajaí: Univali, 1998. $92 \mathrm{p}$.

IBGE - Instituto Brasileiro de Geografia e Estatística. Portal Cid@des. Disponível em: <www.ibge.gov.br/cidadesat> Acesso em: 2 ago. 2007.

IONESCU, C.; R.J.T. KLEIN; K.S. KAVI KUMAR; J. HINKEL AND R. KLEIN. Towards a Formal Framework of Vulnerability to Climate Change. NeWater Working Paper 2 and FAVAIA Working Paper 1. Potsdam Institute for Climate Impact Research, Potsdam, Germany, ii+20 pp, 2005.

LELIS, R. J. F. Variabilidade da linha de costa oceânica adjacente às principais desembocaduras do Rio Grande do Sul. Rio Grande, 2003. Monografia de graduação, Fundação Universidade Federal de Rio Grande. 79 p.

LIMA, D. C. C. Aplicação de imagem do satélite LANDSAT TM5 e de fotografias aéreas verticais para o mapeamento dos recifes costeiros e análise dos processos físicos litorâneos relacionados (Tamandaré - PE - Brasil). Recife, 2003. Dissertação de mestrado, Universidade Federal de Pernambuco. 119 p

LIRA, A. R. A. Caracterização morfológica e vulnerabilidade do litoral entre as praias da Enseadinha e Maria Farinha, Paulista-PE. Recife, 1997. Dissertação de mestrado, Universidade Federal de Pernambuco. 96 p.

MANSO, V. A. V; TOLDO JR., E.; MEDEIROS, C.; ALMEIDA, L. E. S. B. Perfil praial de equilíbrio da praia de Serinhaém, Pernambuco. Revista Brasileira de Geomorfologia, Uberlândia, v. 2, n. 1, p. 45- 49, 2001. 
MCCARTHY, J. J.; CANZIANI, O. F.; LEARY, N. A.; DOKKEN, D. J.; WHITE, K. S. (Eds.). Climate Change 2001: Impacts, Adaptation and Vulnerability. In: Contribution of Working Group II to the Third Assessment Report of the Intergovernmental Panel on Climate Change. Cambridge: Cambridge University Press, $x+1032$ pp. Disponível em: http://www.ipcc.ch/ipccreports/tar/wg2/index.htm Acesso em: 20 mar. 2007.

PENDLETON, E. A.; WILLIAMS, S. J.; THIELER, E. R. Coastal vulnerability assessment of Assateague Island National Seashore (ASIS) to sea-level rise. U.S. Geological Survey Open-File Report 2004-1020, Electronic Book. 20 p. Disponível em:

<http://woodshole.er.usgs.gov/project-pages/nps-cvi/> Acesso em: 22 jan. 2007.

SOUZA, C. R.; SUGUIO, K.; OLIVEIRA, A. M. S.; OLIVEIRA, P. E. (Org.). Quaternário do Brasil. Ribeirão Preto: Ed. Holos, 2005. 382 p

THIELER, E. R.; HAMMAR-KLOSE, E. S. National assessment of coastal vulnerability to sealevel rise, Preliminary Results for the U. S. Atlantic Coast. Massachusetts: U. S. Geological Survey Open-file Report, 99-593. 1999. Disponível em: $\leq$

http://pubs.usgs.gov/of/1999/of99-593/> Acesso em: 30 abr. 2007.

TOLDO JR., E. Obras de Proteção e Estabilização da Praia/ Processos Costeiros.

Porto Alegre, 2006. 11 p. (Não publicado). 